NUREG/CR-5857

ORNL-6713

\title{
Aging of Turbine Drives for Safety-Related Pumps in Nuclear Power Plants
}

Manuscript Completed: March

Date Published: June 1995

Prepared by

D. F. Cox

Oak Ridge National Laboratory

Managed by Martin Marietta Energy Systems, Inc.

Oak Ridge National Laboratory

Oak Ridge, TN 37831-6285

\section{Prepared for}

Division of Engineering Technology

Office of Nuclear Regulatory Research

U.S. Nuclear Regulatory Commission

Washington, DC 20555-0001

NRC Job Code B0828 



\section{DISCLAIMER}

This report was prepared as an account of work sponsored by an agency of the United States Government. Neither the United States Government nor any agency thereof, nor any of their employees, make any warranty, express or implied, or assumes any legal liability or responsibility for the accuracy, completeness, or usefulness of any information, apparatus, product, or process disclosed, or represents that its use would not infringe privately owned rights. Reference herein to any specific commercial product, process, or service by trade name, trademark, manufacturer, or otherwise does not necessarily constitute or imply its endorsement, recommendation, or favoring by the United States Government or any agency thereof. The views and opinions of authors expressed herein do not necessarily state or reflect those of the United States Government or any agency thereof. 


\section{DISCLAIMER}

Portions of this document may be illegible in electronic image products. Images are produced from the best available original document. 


\begin{abstract}
This study was performed to examine the relationship between time-dependent degradation and current industry practices in the areas of maintenance, surveillance, and operation of steam turbine drives for safety-related pumps. These pumps are located in the Auxiliary Feedwater (AFW) system for pressurized-water reactor plants and in the Reactor Core Isolation Cooling and High-Pressure Coolant Injection systems for boiling-water reactor plants. This research has been conducted by examination of failure data in the Nuclear Plant Reliability Data System, review of Licensee Event Reports, discussion of problems with operating plant personnel, and personal observation. The reported failure data were reviewed to determine the cause of the event and the method of discovery. Based on the research results, attempts have been made to determine the predictability of failures and possible preventive measures that may be implemented.
\end{abstract}

Abstract

Findings in a recent study of AFW systems indicate that the turbine drive is the single largest contributor to AFW system degradation. However, examination of the data shows that the turbine itself is a reliable piece of equipment with a good service record. Most of the problems documented are the result of problems with the turbine controls and the mechanical overspeed trip mechanism; these apparently stem from three major causes:
1. Originally designed as a continuous drive mechanism with a slow startup sequence, the safety-related turbines are used in standby service with normal startup in $\sim 30 \mathrm{~s}$. The turbines are typically only run from once a month to once a quarter during pump testing. The data indicate that this lack of operation can actually be a major contributor to turbine degradation. Moisture trapped inside the turbine and controls can cause damaging corrosion to the governor and the governor valve.

2. Historically, maintenance practices have resulted in corrective maintenance being performed instead of preventive/predictive maintenance.

3. Design changes by the manufacturer have been implemented with varying degrees of success because of the change in service requirements from the original design requirements.

Recent improvements in maintenance practices and procedures, combined with a stabilization of the design, have led to improved performance resulting in a reliable safety-related component. However, these improvements have not been universally implemented. 



\section{Contents}

\section{Page}

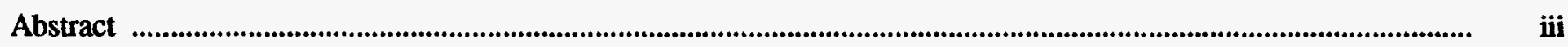

List of Figures

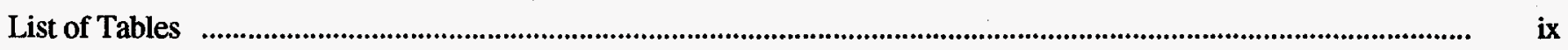

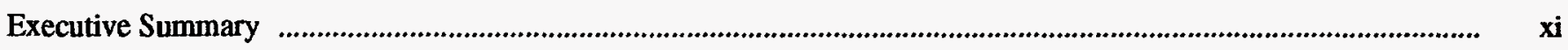

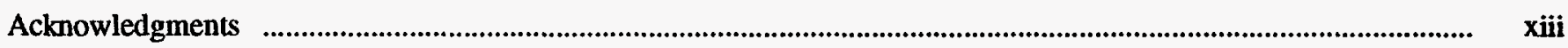

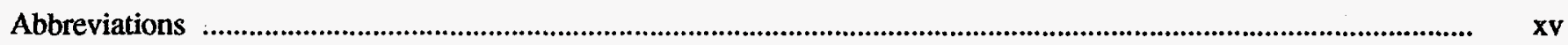

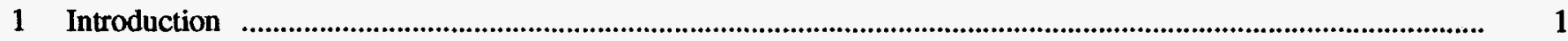

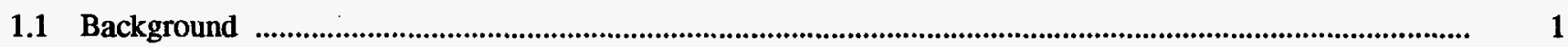

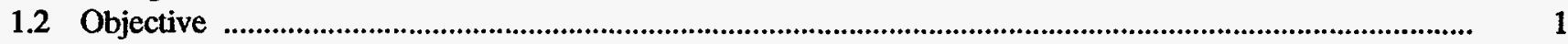

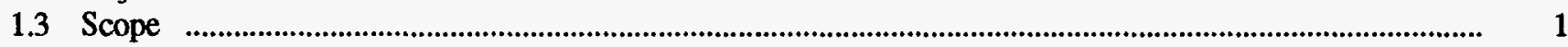

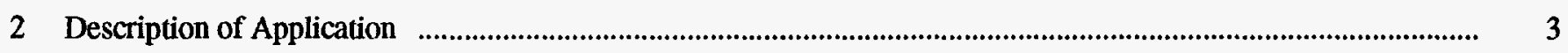

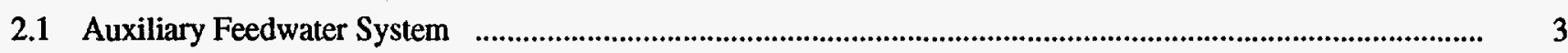

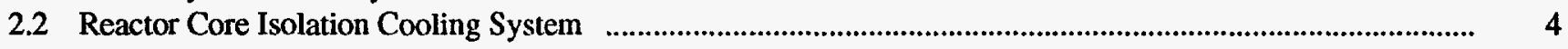

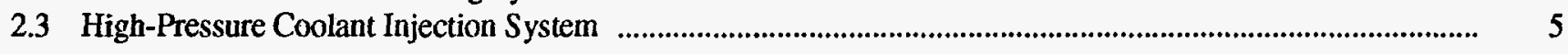

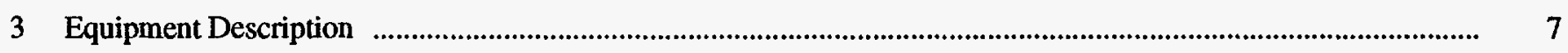

3.1 AFW/RCIC Turbine Description-Operation Overview and Component Function Summary $\quad \ldots . . . . . . . . . . . . . . . . . . . . \quad 7$

3.1.1 Steam Admission Valve ....................................................................................................... 8

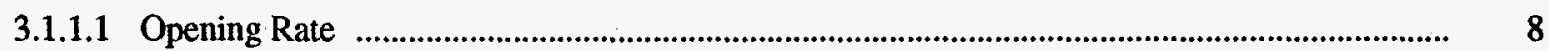

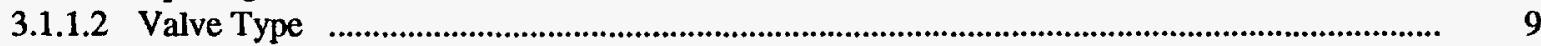

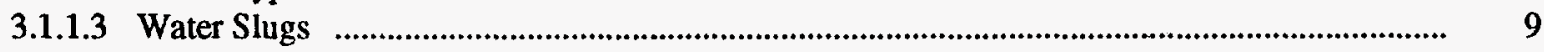

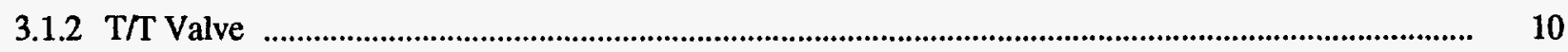

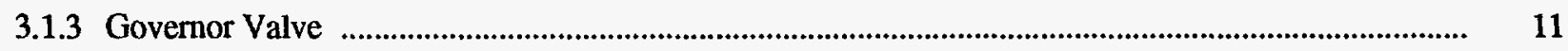

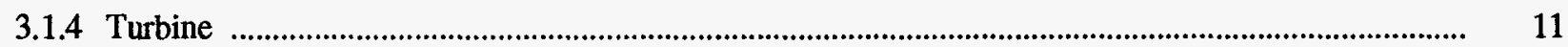

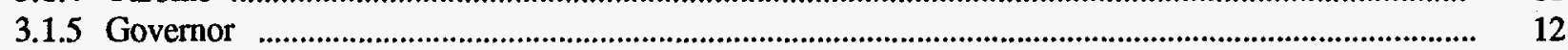

3.1.6 Overspeed Trip Mechanism .......................................................................................................... 12

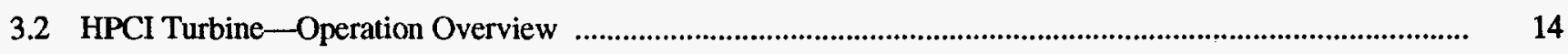

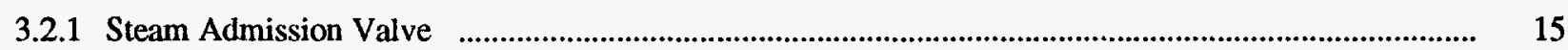

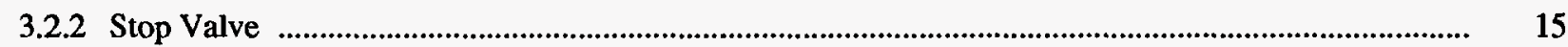

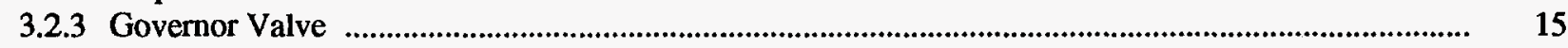

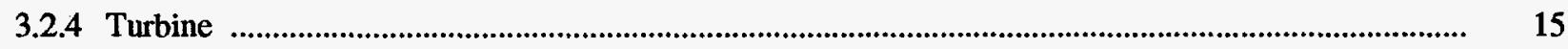

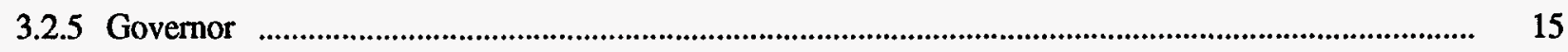

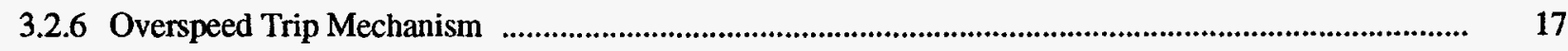

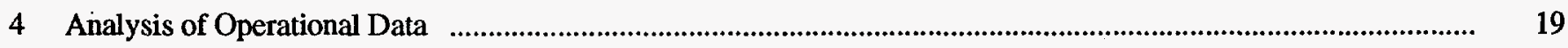

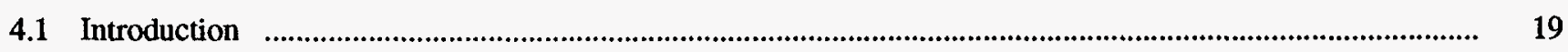

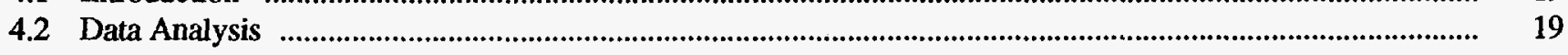

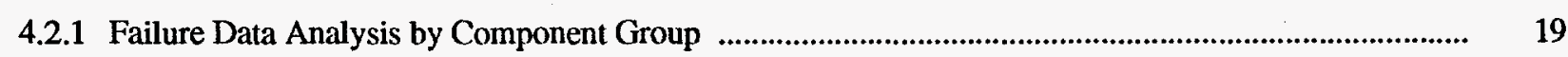

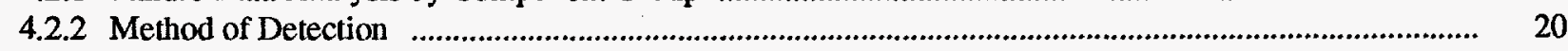

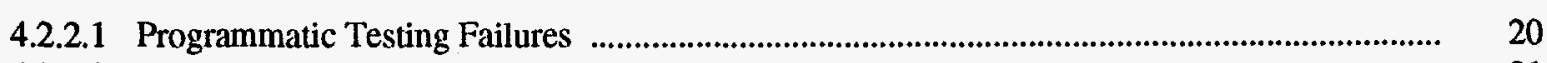

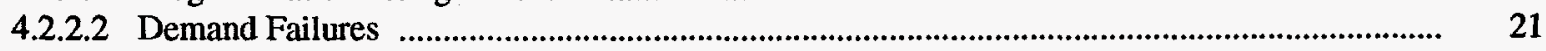

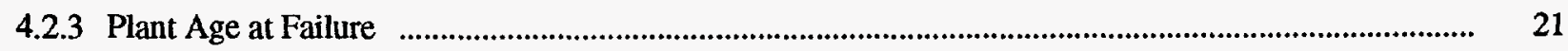

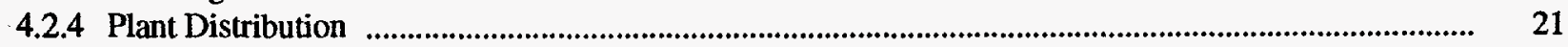




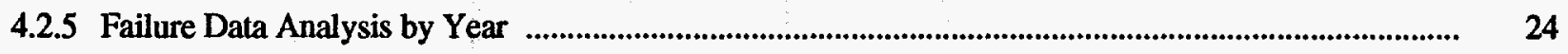

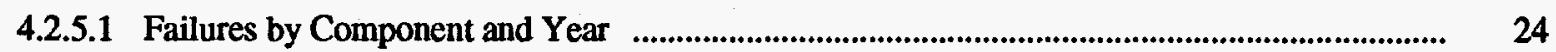

4.2.5.2 Failures by Method of Detection and Year ................................................................................ 24

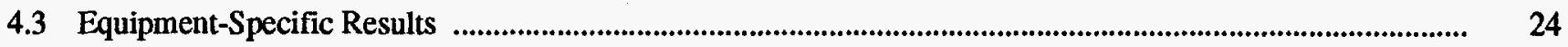

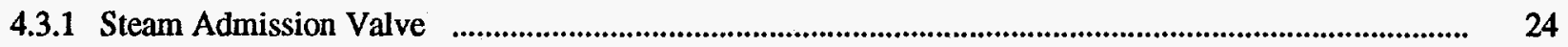

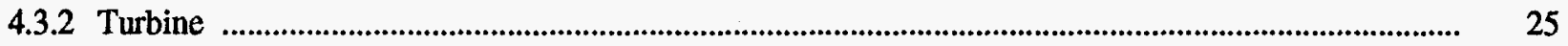

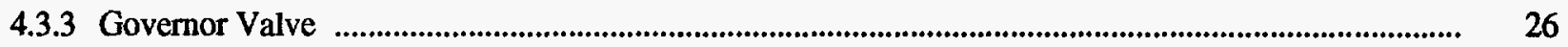

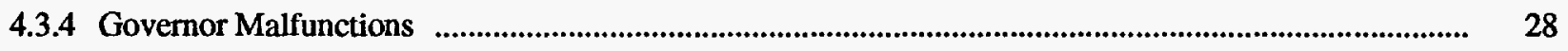

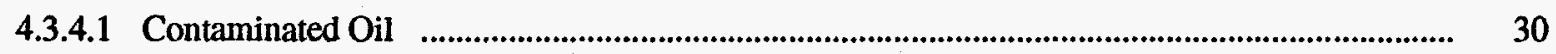

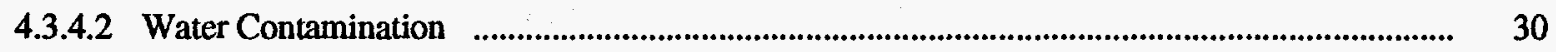

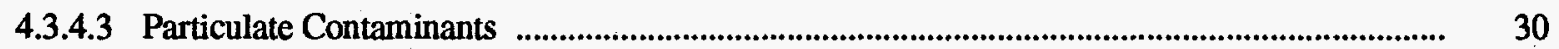

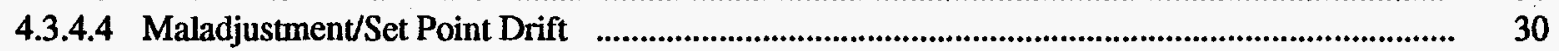

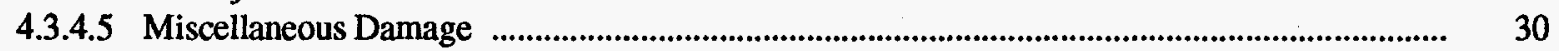

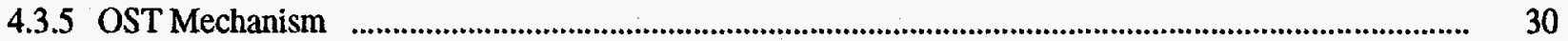

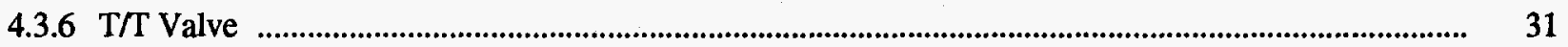

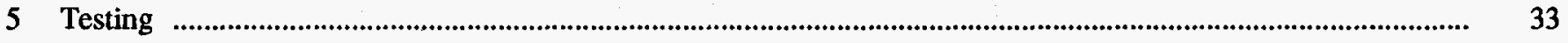

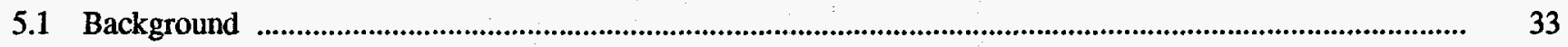

5.2 Current Requirements ..................................................................................................................................... 33

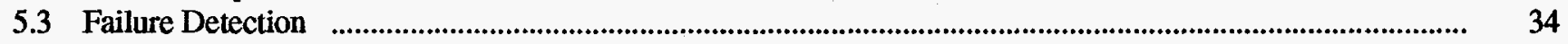

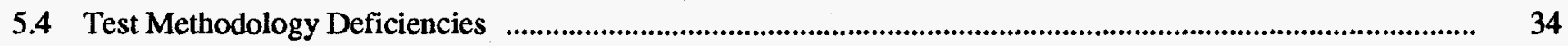

5.5 Vendor Recommendations ........................................................................................................................ 34

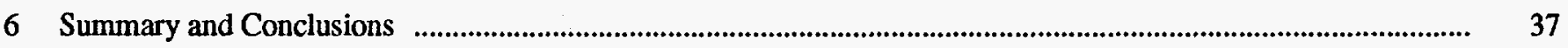

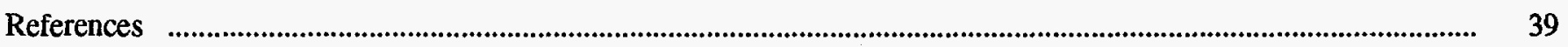

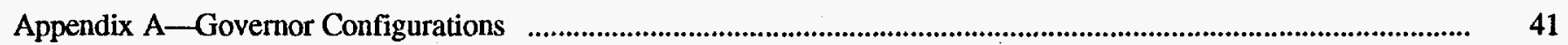




\section{List of Figures}

Typical AFW system

Major components of turbine system

Percentage of full flow vs disk travel for typical gate valve

$\mathrm{T} / \mathrm{T}$ valve internals

$21 / 2$-in. governor valve

3-in. governor valve

3.7

Basic turbine configuration

Electronic governor remote (EGR) schematic Mechanical OST mechanism

HPCI stop valve

HPCI trip valve assembly

4.1

4.2

Percentage of total failures by component

18

4.3

Failure by method of detection

19

4.3
4.4

4.5

4.6

4.7

4.8

4.9

Failures discovered programatically

20

Demand failures per year

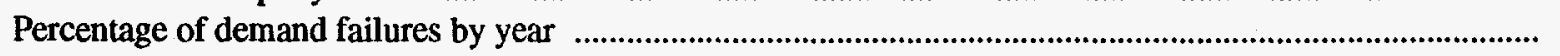

Normalized turbine age at failure

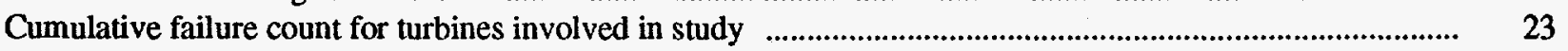

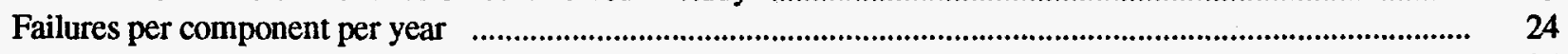

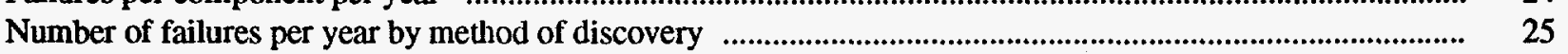

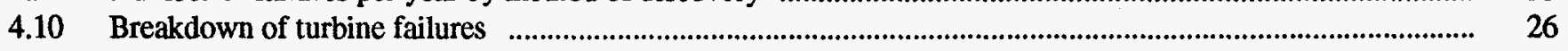

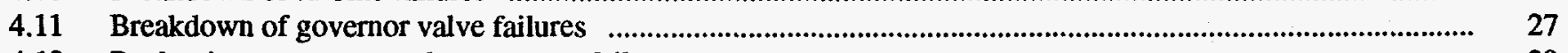

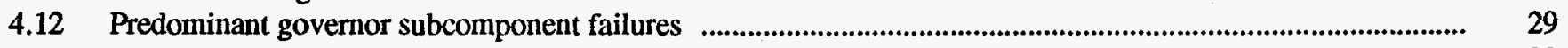

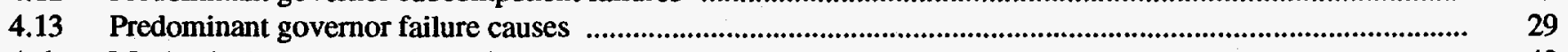

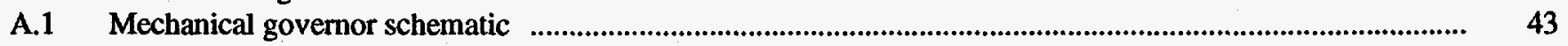

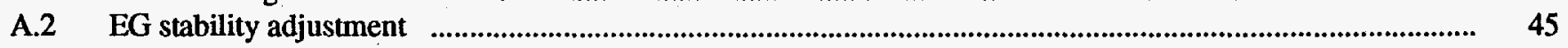

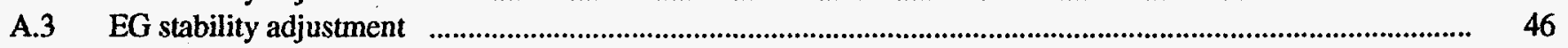




\section{List of Tables}

Table

Page

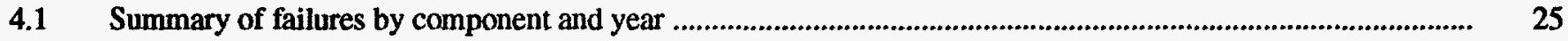

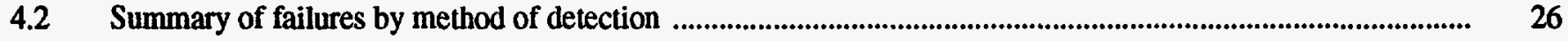

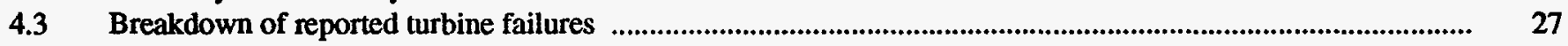

$4.4 \quad$ Breakdown of reported governor valve failures ................................................................................................. 28

4.5 Predominant governor failure causes ............................................................................................................. 30

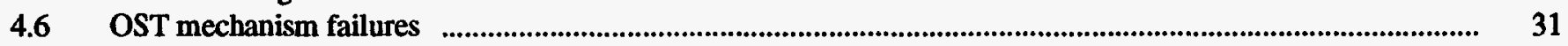





\section{Executive Summary}

Steam turbine drives for safety-related pumps are used at most commercial nuclear power plants in the United States. Turbine-driven pumps are used in pressurized-water reactors in the Auxiliary Feedwater (AFW) system to provide diversity and increase protection against a common mode failure such as motor failure, which could cause the loss of the motor-driven pumps. Turbine-driven pumps are also used at boiling-water reactor (BWR) sites. For BWRs they are located in the Reactor Core Isolation Cooling and the High-Pressure Coolant Injection systems. During loss of all ac power these pumps provide the only means for supplying emergency cooling water to the systems responsible for decay heat removal and/or for keeping the core covered. A brief description of each system along with turbine operating conditions is presented in Chap. 2.

The components evaluated were restricted to the major components of the turbine system and their subcomponents. The six major components are the turbine, governor controls, governor valve, overspeed trip (OST) mechanism, steam admission valve, and trip and throttle valve. The analysis of historical failure data indicates that the majority of failures are confined to these components.

\section{Data Analysis}

Historical failure* data were gathered from Licensee Event Reports and the Nuclear Plant Reliability Data System and placed in a data base. The data collected included the reporting site, description narrative, cause narrative, corrective action narrative, date of failure start, and method of failure detection. Additional fields were added for the creation of codes to permit categorization. These codes included the major subcomponent group (functional grouping), the subcomponent itself (the piece part, or subcomponent actually involved in the failure), and the cause, a code assigned to the failure based on a review of the event description independent of the cause reported by the utility.

The failure records were reviewed and characterized by component group, method of detection, calendar year, and affected plant.

Evaluation of the data after categorizing by component group reveals the governor as the single component that

\footnotetext{
*For this report a failure is defined as a state of turbine degradation that restricts, prevents, or otherwise degrades turbine function. Incipient failures were not considered.
}

fails most often, followed by the turbine, the OST mechanism, and the governor valve. Discussion of failures per component group are presented in Sect. 4.2.1 with component specific details discussed in Sect. 4.3.

The majority of the failures examined were discovered by programmatic means. Programmatic discoveries outnumbered demand discoveries by almost a factor of 3 to 1 . Programmatic discoveries include routine surveillance testing, in-service inspection, and routine observation by system engineers who walk down systems on a regular basis. The examined data indicate that the highest percentage of failures was detected during scheduled testing (55\%). This trend was consistent for each year examined. The second most prevalent method of detection was a demand failure (20\%), followed by the combination of routine and incidental observation (13\%). Failures by method of detection are discussed in Sect. 4.2.2.

The data indicate that the maximum number of failures per year occur at a turbine age of 10 to 15 years. This means that there were more failures of turbines in this age bracket than of turbines at any other age.

Evaluation of the data on a failures per plant basis reveals that a relatively small number of plants contribute the majority of failures. Examination of the data reveals that only 7 of 86 plants contribute $25 \%$ of the failures, and only 18 of 86 plants contribute 187 of the 375 failures $(-50 \%)$. No significant distinction was made between PWRs or BWRs. However, the reader is cautioned against drawing conclusions based on this limited amount of data. Many variables could potentially contribute to this finding. The quality of reporting by individual utilities varies from plant to plant. Reporting may even change at the same plant based on a certain time period. There have also been instances where failures accumulated against a particular plant while the vendor went through an iterative process of subcomponent redesign and replacement.

\section{Testing Requirements}

Testing of the turbine is primarily performed to accomplish periodic testing of the associated pump. Verification of turbine operability is not an explicit technical specification requirement; rather, the turbine is addressed only in the context of the pump that it drives. Of primary interest during turbine testing is verification that the speed control system is functioning properly. This includes the governor, governor valve, servomotor, and associated linkages. 


\section{Executive}

Operation of the turbine over the full range of steam supply pressures should be verified.

Once per month (typically) the AFW system is required, by technical specifications, to be started. The system must demonstrate that the pump can deliver a specified flow at a specified pressure. The flow/pressure combination is not required to be at design conditions and is typically conducted with the pump operating under miniflow conditions. Full flow testing at design pressures is not required and is not commonly practiced.

An apparent difficulty with these requirements is that turbine operability is not demonstrated for the full range of design operating conditions. As discussed in Chap. 2, the function of the AFW system is to supply water that is turned into steam, thus removing decay heat from the reac- tor. The goal is to reduce the reactor temperature below $350^{\circ} \mathrm{F}$, at which time the Residual Heat Removal (RHR) system initiates. Because the turbine steam supply comes from the steam generators, a reduction in the steam generator temperature (based on reduced reactor temperature) will consequently reduce the pressure of the steam supplied to the turbine. Note that saturation pressure for $350^{\circ} \mathrm{F}$ is about 120 psig. A reduction in the steam supply pressure will reduce the amount of steam admitted to the turbine for a given governor valve position. Therefore, the governor valve must open further to maintain the turbine "on speed." If the turbine is not tested at these lower supply pressures, there is no verification that the speed control system will maintain turbine control and stability at the point of operation before RHR actuation. For example, deformities in the governor valve stem near the end of travel limits (corrosion or bent stem) may not affect speed control until the point of deformity comes in contact with the governor valve packing. 


\section{Acknowledgments}

The guidance provided by D. A. Casada and W. S. Farmer has proven invaluable in the preparation of this document. The assistance provided by W. P. Poore during data collection and the insights of J. Kelso during data analysis have also proven to be of great value. Deepest gratitude is also extended to W. R. Tomlinson and all of the other utility personnel whose experiences and insights made this document possible.

Thanks are also expressed to all of the vendor employees who took the time to share information with the author.
Their contributions in understanding the equipment are priceless. The cooperation of the utilities that allowed the author to spend time at their facilities, interacting with employees during the performance of maintenance tasks, is also gratefully acknowledged.

Finally, deepest thanks to the peers and colleagues who provided insights, viewpoints, and experiences that are indispensable. 



\section{Abbreviations}

$\begin{array}{ll}\text { AEOD } & \text { Office for Analysis and Evaluation of Data } \\ \text { AFW } & \text { auxiliary feedwater } \\ \text { BWR } & \text { boiling-water reactor } \\ \text { EG } & \text { electronic governor } \\ \text { EGR } & \text { electronic governor remote } \\ \text { EGM } & \text { electronic governor speed control } \\ \text { HPCI } & \text { High-Pressure Coolant Injection } \\ \text { LER } & \text { Licensee Event Report } \\ \text { LOCA } & \text { loss-of-coolant accident } \\ \text { LPCI } & \text { Low-Pressure Coolant Injection } \\ \text { NPRDS } & \text { Nuclear Plant Reliability Data System }\end{array}$

$\begin{array}{ll}\text { NRC } & \text { Nuclear Regulatory Commission } \\ \text { OST } & \text { overspeed trip } \\ \text { PG } & \text { pressure-compensating governor } \\ \text { PWR } & \text { pressurized-water reactor } \\ \text { RCIC } & \text { Reactor Core Isolation Cooling } \\ \text { RCS } & \text { reactor coolant system } \\ \text { RHR } & \text { residual heat removal } \\ \text { RGSC } & \text { ramp generator signal converter } \\ \text { SAV } & \text { steam admission valve } \\ \text { SG } & \text { steam generator } \\ \text { T/T } & \text { trip and throttle }\end{array}$




\section{Introduction}

\subsection{Background}

Steam turbine drives for safety-related pumps are used at most of the commercial nuclear power plants in the United States. Turbine-driven pumps are used in pressurized-water reactors (PWRs) in the Auxiliary Feedwater (AFW) system to provide diversity and increase protection against a common mode failure such as motor failure, which could cause the loss of the motor-driven pumps. Turbine-driven pumps are also used at boiling-water reactor (BWR) sites. For BWRs they are located in the Reactor Core Isolation Cooling ( $\mathrm{RCIC}$ ) and the High-Pressure Coolant Injection (HPCI) systems. During loss of all ac power these pumps provide the only means for supplying emergency cooling water to the systems responsible for decay heat removal and/or for keeping the core covered. A recent aging study of the AFW system identified the turbine drive as the single largest contributor to AFW system degradation.

The June 9, 1985, loss of feedwater event at Davis Besse Unit 1 is a good example of the problems that can occur when there is an undesired trip of the pump turbine. During this event both AFW pump turbines tripped on overspeed. This forced the utility to use the motor-driven nonsafetyrelated startup feed pump, which also had to be manually started. Equipment operators were required to manually start both turbines. Automatic control of the turbines was not regained during the event. In contrast, on January 31 , 1989, the turbine at Rancho Seco failed to trip during an overspeed condition. The failure of the overspeed trip (OST) mechanism resulted in an overpressurization of the pump discharge piping. The system design pressure is $1325 \mathrm{psig}$. The calculated discharge pressure, based on the turbine speed at the time that it was shutdown, was 3850 psig, thereby causing a 2525-psig overpressurization. ${ }^{1}$ These events support the statement that "review of the failure data indicated that a few types of AFW system components were responsible for a large fraction of system degradation." 2 Due to these events, and others like them, more attention is being paid to the reliability of steam-driven turbines.

The turbine drives were originally designed for commercial-use driving equipment at petroleum, chemical, and fossil power plants. In commercial applications the turbines are started slowly and run continuously. When run in this manner the turbines have operated reliably. For nuclear service, however, the turbines are used in a standby capacity and are operated most often during surveillance testing. Rapid starting of the turbine causes a demanding challenge to the turbine speed control system. Even minor degrada- tion of the control system, such as condensate in the governor oil, can result in a turbine OST during startup. Long idle periods may contribute to the collection of condensate, which must be removed from the system before proper operation, and to the formation of corrosion on components such as the governor valve stem or governor internals. Both of these events can lead to increased degradation of the turbine and turbine control system.

\subsection{Objective}

This study includes the identification of failure modes, the identification of failure causes, and a review of inspection/ surveillance practices. The findings are based on a review of operating experience for the components and historical problems that are documented in the Nuclear Plant Reliability Data System (NPRDS), regulatory documents (information notices), Licensee Event Reports (LERs), and industry literature [General Electric Company (GE) service information letters].

The review of the failure data has resulted in some recommendations for specific maintenance and testing practices that are designed to reduce demand failures and failures that would lead to system unavailability during a demand situation.

\subsection{Scope}

The components examined were restricted to the major components of the turbine system (which is bought as a package). The six major components that make up the turbine system are the turbine itself, governor, governor valve, OST mechanism, steam admission valve (SAV), and trip and throttle (T/T) valve. Often, industry references to the "turbine" are actually references to the turbine system. Analysis of historical failure data indicates that the majority of failures are confined to these components.

Historical failure data were obtained by searching the NPRDS and LERs for failure causes, a narrative description of the event, and identification of the involved components or subcomponents. The historical data searches were combined with interviews of nuclear plant personnel and industry experts to identify problems or trends that may not have been apparent in the reported data.

NPRDS contains incomplete data for the time period before 1984; therefore, data for the time period before 1984 were 
omitted. Also note that a report (C602) by the Nuclear Regulatory Commission (NRC) Office for Analysis and Evaluation of Data (AEOD) covers the time period from 1972 to 1985 . The conclusion of AEOD/C602 was that
“... the dominant attributed causes of AFW turbine overspeed trips are speed control problems associated with governors, and trip and reset problems associated with trip valves and overspeed trip mechanisms."3 


\section{Description of Application}

\subsection{Auxiliary Feedwater System}

The AFW system's ${ }^{2}$ principal role is to support removal of stored and decay heat from the reactor coolant system (RCS). The steam generators (SGs) act as a heat sink during both normal operation and following reactor trips. During normal operation, the main feedwater system provides feedwater to the SGs, where it is converted to steam and then used to drive the main turbine and provide process steam for various plant equipment. During normal power operation, the AFW system is in standby (except when being tested). Following an operating transient or accident, as well as during routine startups and shutdowns, the AFW system is used to provide a safety-related source of water to the SGs (see Fig. 2.1). The water delivered by the AFW system is heated and vaporized in the SGs. Steam thus generated can be released to the atmosphere through the safety-related main steam safety valves or atmospheric dump valves or to the atmosphere and/or condenser through nonsafety-related steam dump valves.
The AFW system must not only support the heat removal but allow it to take place in a controlled manner even under design basis accident conditions. Four general functional requirements of the AFW system are to

1. provide flow to intact $S G$ following design basis transients/accidents,

2. isolate flow to faulted or ruptured SGs,

3. maintain a liquid barrier between the RCS and the environment following design basis accidents to ensure that any primary to secondary tube leakage is "scrubbed" before release, and

4. support normal startup and shutdown sequences.

As noted, the AFW system is used, at most plants, in support of normal plant startup and shutdown. However, this is not the primary basis for its design. Rather, it is specifically designed for the mitigation of the consequences of design basis transients and accidents, including loss of main feedwater, main feed line break, main steam line break,

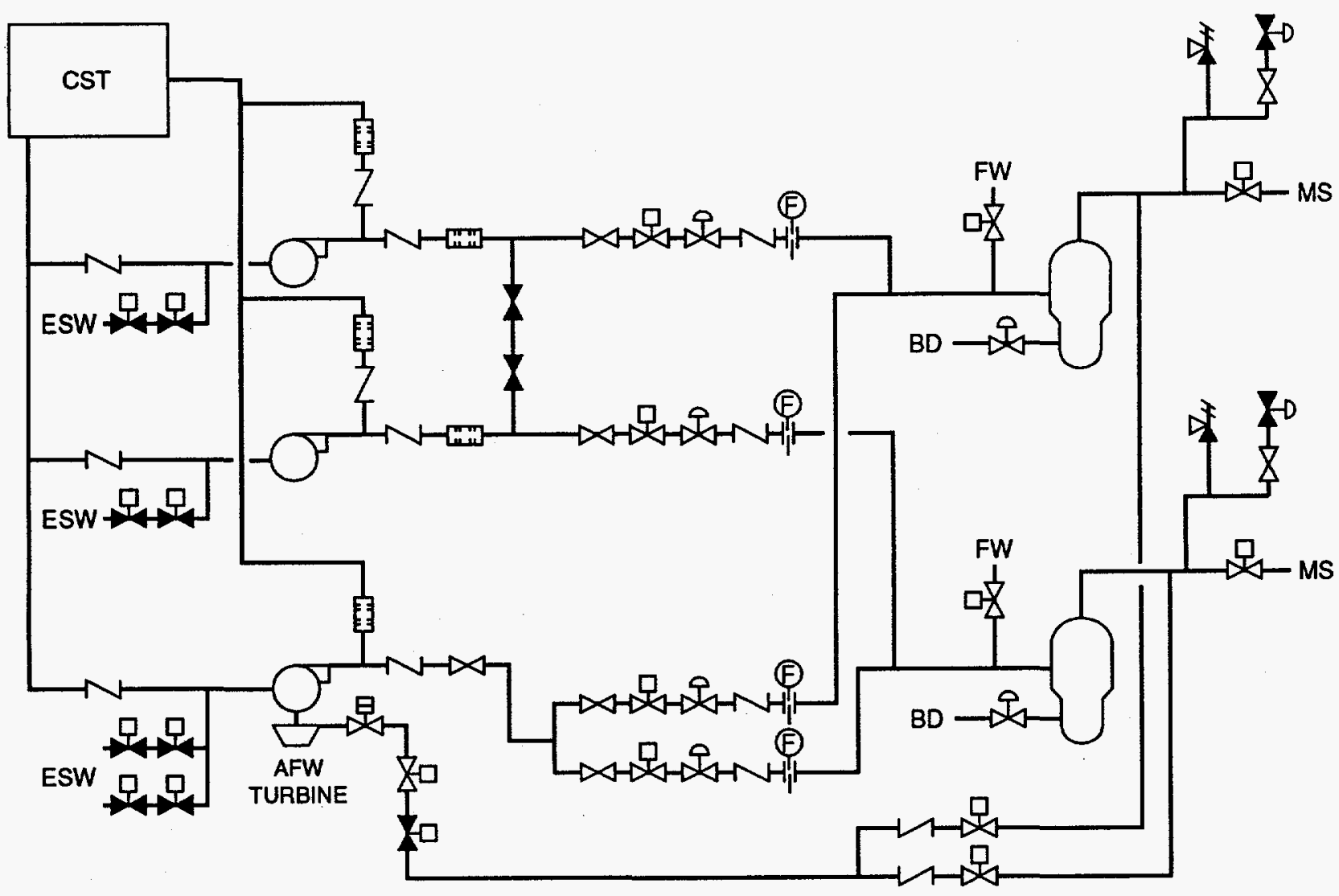

Figure 2.1 Typical AFW system 
small- and large-break loss-of-coolant accidents (LOCAs), SG tube rupture, and others. In addition, proper functioning of the AFW system is critical to the ability of a plant to deal with an important accident condition, station blackout, which has not been historically treated as a design basis accident. For most PWR plants, the turbine-driven pump's performance is critical to station blackout mitigation to prevent a rapid rise in RCS temperature.

The steam supply to the AFW turbine is taken from the SGs through the main steam system. The steam supply pressure can range from a high that corresponds to the main steam safety valve cracking pressure ( 1215 psia) to a low of $-120 \mathrm{psia}$. This low pressure corresponds to a temperature of $\sim 340^{\circ} \mathrm{F}$. The AFW is required to operate until the temperature in the reactor is reduced to the point at which the residual heat removal (RHR) can be started $\left(350^{\circ} \mathrm{F}\right.$ ). Because the SGs are a heat sink for the reactor, SG temperature typically must be below $350^{\circ} \mathrm{F}$. Therefore, it is possible that the AFW turbine could be operating with steam supply pressures as low as $\mathbf{1 2 0}$ psia.

\subsection{Reactor Core Isolation Cooling System}

The RCIC system serves two functions. First, it provides makeup water to the reactor vessel when the vessel is iso- lated from the main condenser and the condensate and feedwater systems are unavailable (see Fig. 2.2). The RCIC system may also be used in conjunction with the RHR system in the steam condensing mode to pump condensate from the RHR system back into the reactor. The RCIC operates to prevent the need for the core standby cooling systems (HPCI), and in practice the RCIC is verified operational whenever the HPCI system is out of service.

The RCIC system may be started in two ways. Automatic initiation of the RCIC system results when a low water level in the reactor is detected. The system may also be started remotely from the control room by the unit operator. In either case the system is capable of delivering design flow within $30 \mathrm{~s}$ of initiation.

The system continues in operation until (1) high water levels are detected in the reactor, (2) automatic isolation occurs, or (3) the system is manually shut down.

The system controls will automatically trip the turbine in the event of

1. low pump suction pressure,

2. high turbine exhaust pressure,

3. turbine overspeed,

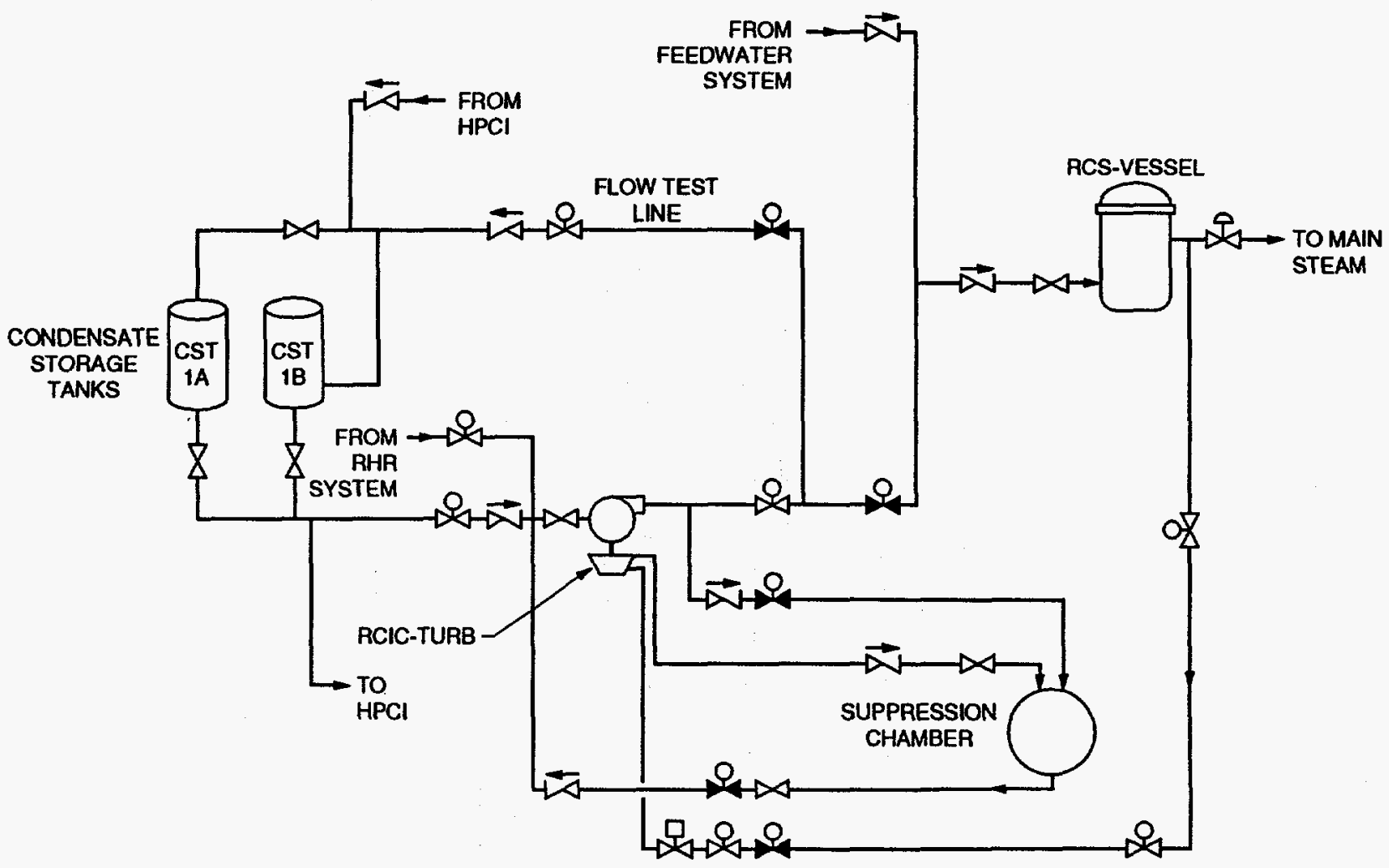

Figure 2.2 Typical RCIC system 
4. RCIC steam line break,

5. high water level in the reactor, or

6. containment isolation.

The steam that drives the turbine is drawn from the main steam line and is supplied at pressures ranging from 150 to 1100 psia. Wide fluctuations in operating pressures are caused by the same conditions as those described for AFW operation. The RCIC system can operate until RHR initiation. Turbine exhaust is directed to the suppression pool.

Controls for the system are powered from the dc safetyrelated power source. The system operates independent of ac power; therefore, loss of off-site power will not jeopardize RCIC system operation.

\subsection{High-Pressure Coolant Injection System}

The HPCI system is designed to provide makeup cooling water to the reactor during small-break accidents that do not result in rapid depressurization of the reactor vessel (see Fig. 2.3). The system is used to ensure that sufficient core level is maintained to limit fuel cladding temperature. This system was replaced on BWR-5 and -6 reactors with the High Pressure Core Spray (HPCS) system. The HPCI system operates until reactor pressure is reduced to the point of Low-Pressure Coolant Injection (LPCI) system initiation or Core Spray system initiation, which can be as low as 150 psia.

The system automatically initiates during a LOCA if the reactor water level decreases to a level that indicates pending core exposure or upon high primary containment pressure. A high vessel water level will trip the system. The system automatically resets and will initiate if the water level decreases to a level that threatens core exposure.

The HPCI turbine is supplied with steam that is generated by residual and decay heat in the reactor. The HPCI system also serves as backup to the RCIC system.

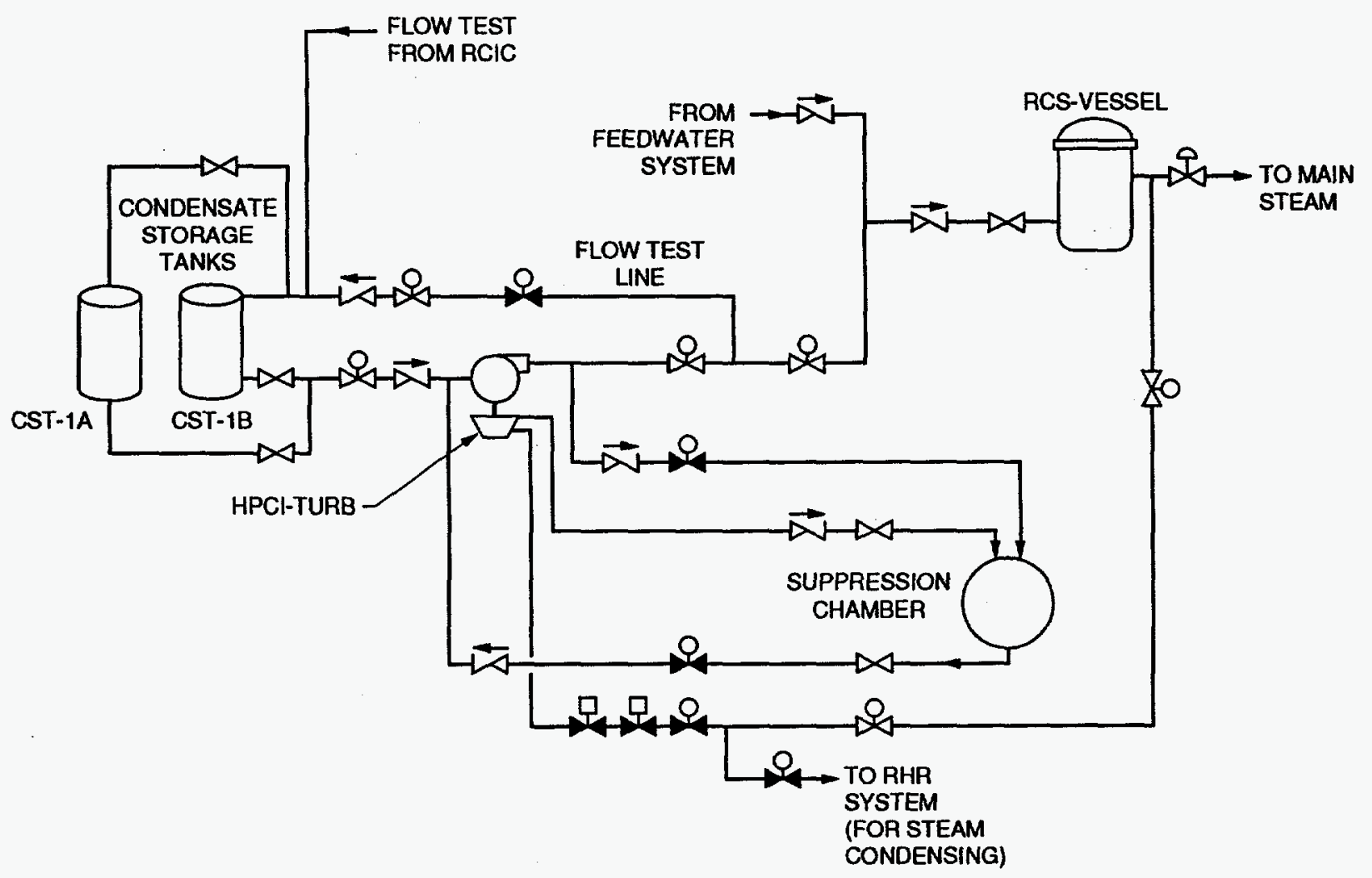

Figure 2.3 Typical HPCI system 



\section{Equipment Description}

\subsection{AFW/RCIC Turbine Description- Operation Overview and Component Function Summary}

On initiation of the AFW/RCIC system, the SAV (or the $T / T$ valve for some plants) opens, admitting steam to the turbine. As the turbine begins to roll, the governor oil pump, which is driven by the turbine shaft, begins to turn and build up hydraulic pressure. At the same time, the governor valve is in its normal startup position (full open). As the turbine continues to accelerate, governor hydraulic pressure increases to the point where the governor valve can be controlled; the governor valve begins to close to maintain the turbine at "idle" speed. After the governor "catches" the turbine acceleration, the turbine ramps up to the reference speed for pump operation or to the speed dictated by the sensors monitoring pump flow output. Once the proper flow is developed, the governor will monitor pump flow vs turbine speed to ensure constant pump flow, regardless of fluctuations in the steam inlet pressure.
The AFW and RCIC turbines are very similar in design and will be considered together during the explanation of the basic turbine system. The majority of the AFW/RCIC turbines are manufactured by the former Terry Steam Turbine Company (currently Dresser Rand) and are GS2 or GS2N models. These particular turbine models are capable of a maximum of 2000-hp output and can operate with steam inlet supply pressures ranging from $<120$ to $>1200$ psia. Typically, the turbine is sized to deliver $\sim 800$ to $900 \mathrm{bhp}$ at about $4000 \mathrm{rpm}$.

The turbine drive system consists of the following major components and subcomponents (Fig. 3.1). Brief descriptions and explanations of the function of each of the major components that comprise the turbine system are provided. More detailed descriptions of the components appear in subsequent subsections.

- SAV - The SAV provides normal isolation of the turbine from the steam supply and at many plants is used to start the turbine.

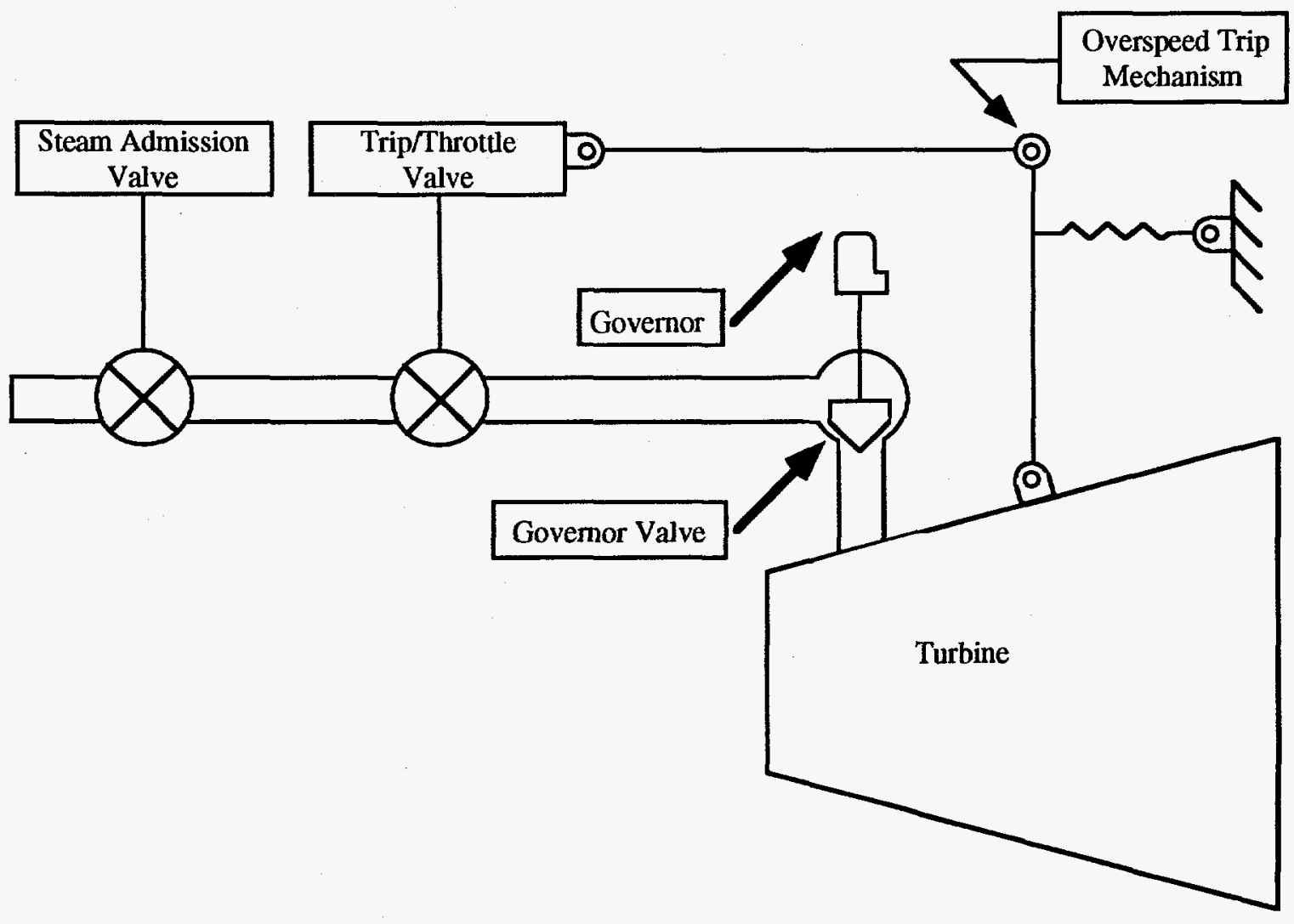

Figure 3.1 Major components of turbine system 


\section{Equipment}

- $T / T$ valve-The $T / T$ valve provides quick isolation of the steam supply to the turbine. It is actuated by the mechanical or electrical OST mechanism upon the occurrence of overspeed. It may also be actuated from the control room to manually trip the turbine. In some plants the $T / T$ valve provides the normal isolation of the steam supply for the turbine. In these plants the T/T valve is used to start the turbine.

- Governor valve-The governor valve regulates the volume of steam admitted to the turbine. The governor valve is positioned by a linkage that is manipulated by the governor servomotor. Servomotor position is based on the error signal from the governor. The governor valve is opened to increase turbine speed or closed to decrease turbine speed, thus maintaining the required flow from the associated pump.

- Turbine-The turbine is the driver for the associated pump. It must maintain speed so that a constant flow is produced by the pump.

- Governor-The governor controls turbine speed by controlling the governor valve position. The governor is designed to maintain turbine speed as turbine load changes.

- Mechanical OST mechanism-The mechanical OST mechanism actuates when the turbine exceeds a predetermined speed to close the T/T valve.

Two types of governors are currently in use at commercial nuclear power stations: pressure-compensating ( $\mathrm{PG}$ ) and electronic governors (EG). The EG series are analog devices and should not be confused with the digital EG currently being marketed by Woodward Governor Company.

The PG series of governors are derivations of the flyball governor. Movement of the flyweight depends on turbine speed, which generates centrifugal force. Changes in turbine speed result in changes to flyweight position. Changes in flyweight position move a plunger, which directs pressurized oil to raise or lower the piston in the servomotor. The servomotor attaches to the governor valve linkage, which directly positions the governor valve.

The EG consists essentially of three separate assemblies: a control box (EGM), speed-adjusting potentiometer, and hydraulic actuator.

The output signal of the EG control box serves as the input signal to the EG hydraulic actuator; the actuator in turn controls the governor valve, which controls the flow of steam to the turbine.

\subsubsection{Steam Admission Valve}

The SAV is not normally supplied as part of the turbine system. However, since it is potentially a major factor in reliable turbine starts, it will be considered within the boundary of this study.

This valve may be used in one of two ways relative to turbine starts. In the first case the SAV is normally closed, and the $T / T$ valve is normally open. In this scenario the SAV is used for turbine starts. When this configuration is used, the distance between the SAV and the turbine T/T valve or the turbine stop valve may be significant. Long runs of unheated pipe either upstream or downstream of the SAV may result in condensation. Also, a certain amount of steam may condense in the supply piping when the SAV is initially opened. If not properly drained, condensate from any of these sources can enter the governor valve at turbine start and cause OSTs (see Sect. 3.1.1.3). ${ }^{4}$

The second case has the SAV normally open, permitting steam up to the $T / T$ valve, and the $T / T$ valve is normally closed. In this arrangement the turbine is started with the $\mathrm{T} / \mathrm{T}$ valve. This configuration is less susceptible to condensation problems because the $T / T$ valve is close to the turbine. Regardless of which valve is used to start the turbine, the rate at which the valve is opened is important to the ability of the governor to control speed during startup.

The initial rate of steam flow into the turbine is a function of (1) valve opening rate and (2) valve type.

\subsubsection{Opening Rate}

Operating experience indicates that the initial rate of flow into the turbine can affect reliable turbine starts. While getting the system on-line as soon as possible is always desirable for safety-related systems, there is a point at which steam can be admitted to the turbine so fast that the governor/governor valve cannot respond in time to prevent OSTs. This happens because the governor valve is at full open when the turbine starts (with the turbine sensing zero speed). Governor hydraulic pressure does not start to build until there is turbine movement. Therefore, at the instant the turbine starts to roll, the speed control system is not able to respond. One utility contacted during the study noted that if the SAV stroke time was reduced below $\sim 8 \mathrm{~s}$, the turbine would begin to trip on overspeed during automatic starts. 


\subsubsection{Valve Type}

The valve type determines the flow transient when the transition is made from steam isolation to steam admission. Ideally, steam will be slowly admitted to the turbine, allowing the governor to establish control oil pressure. The governor control system relies on a turbine shaft-driven oil pump for control oil pressure. Turbine rotation is necessary for the development of oil pressure, and therefore the establishment of speed control is necessary prior to ramping the speed up to operating levels. Figure 3.2 shows a desirable steam flow to disk travel relationship for SAVs. Gate valves, which are commonly used for this service, have flow characteristics that are opposite those considered to be ideal. The change in the rate of flow for a gate valve is greatest when the valve is closest to its seat (Fig. 3.3). If opened too quickly, a typical gate valve can pass critical flow for turbine operation before the governor establishes speed control of the turbine, which can result in an OST.

\subsubsection{Water Slugs}

Water slugs can be the result of a combination of either SAV leakage, ineffective condensate removal devices, or unheated lengths of pipe between the SAV and the T/T valve.

In situations where the $T / T$ valve is normally open and the turbine is started by opening the SAV, there is the potential for condensate to collect downstream of the SAV due to SAV leakage. When this occurs, the slug of condensate is propelled in front of the steam admitted for a turbine start. Because the condensate imparts a smaller amount of energy

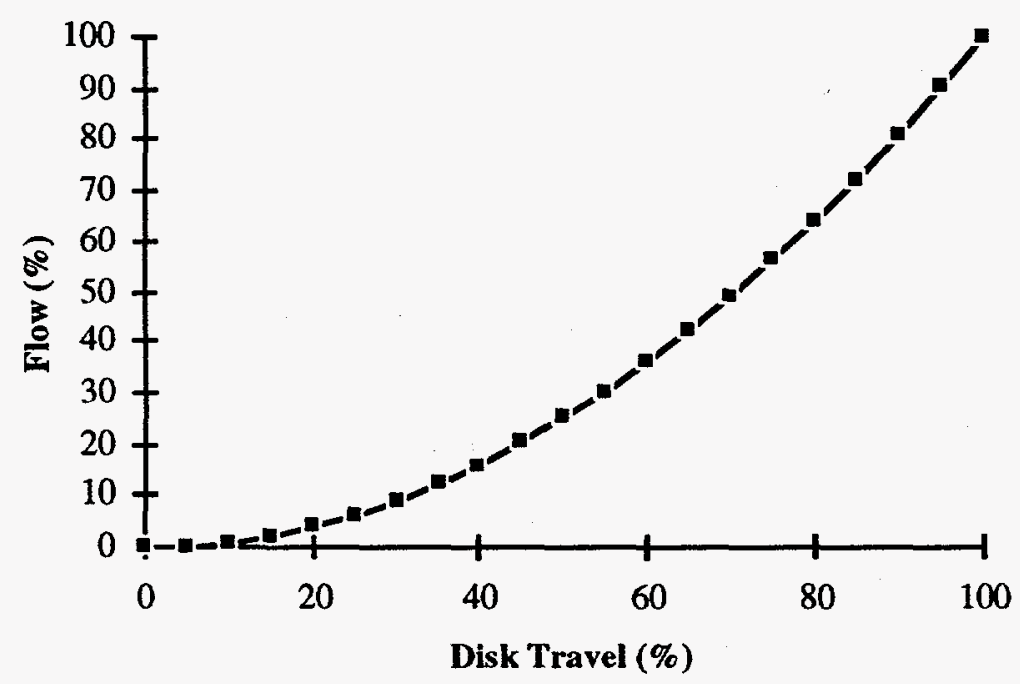

Figure 3.2 Ideal flow through SAV

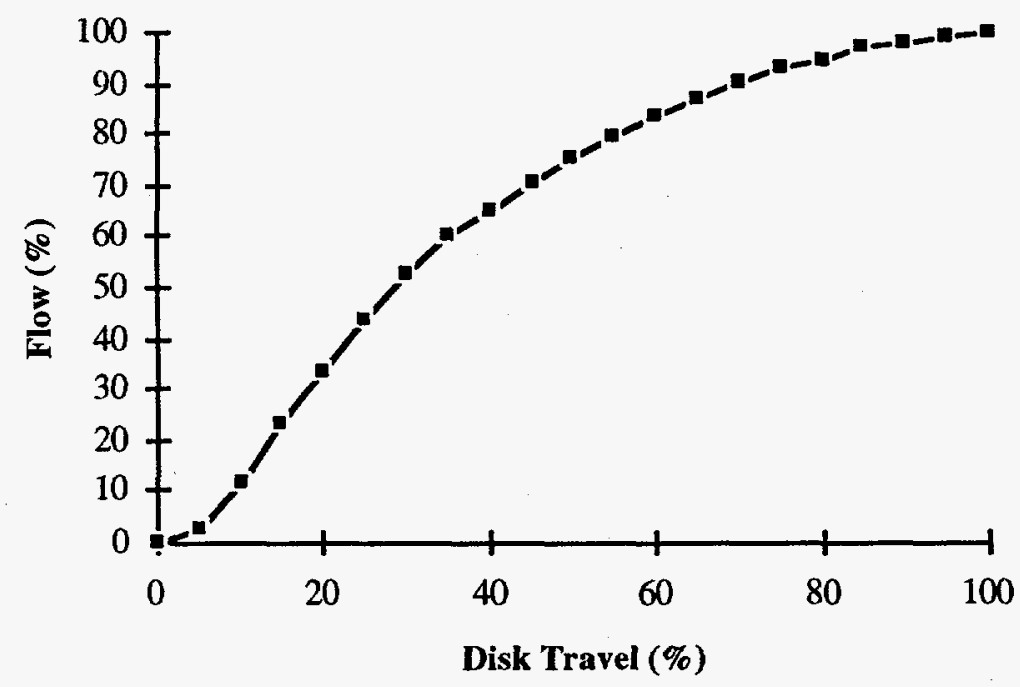

Figure 3.3 Percentage of full flow vs disk travel for typical gate valve 


\section{Equipment}

to the turbine than steam, the governor valve remains full open in an attempt to drive the turbine at the required pump speed. When the condensate has been cleared, the turbine is faced with steam, which has a higher amount of energy per volume than the condensate. The turbine then rapidly accelerates to the overspeed condition faster than the governor valve can respond. This condition can also occur when there is no SAV leakage. If there is an unheated length of pipe between the SAV and the governor valve, the initial volume of steam admitted tends to condense on the cold pipe. This condensate slug is then propelled in the same manner as SAV leakage.

Condensate collection systems, such as condensate pots with automatic level control valves or steam condensate traps, can help avoid or minimize condensate slugging. It is critical, however, that piping be appropriately sloped and the condensate collection devices be properly sized and functioning to prevent excess condensate being carried to the turbine.

\subsubsection{T/T Valve}

The $T / T$ valve (Fig. 3.4) is a globe-type valve configured such that flow is over the seat. The valve utilizes a balance chamber above the disk to reduce required opening forces.

The $T / T$ valve is used to quickly stop steam flow into the turbine when there is an OST actuation. It may also be used to trip the turbine when there is evidence of a pipe break (high steam flow), when the steam generator level is high, when main feedwater has been restored, or for any other reason system use is no longer required. As previously indicated, the $T / T$ valve is used to start the turbine at some plants. The T/T valve is located only a few feet from the turbine. Therefore, the potential for the accumulation of slugs of condensate downstream of the valve is decreased from the configurations that start the turbine with the SAV.

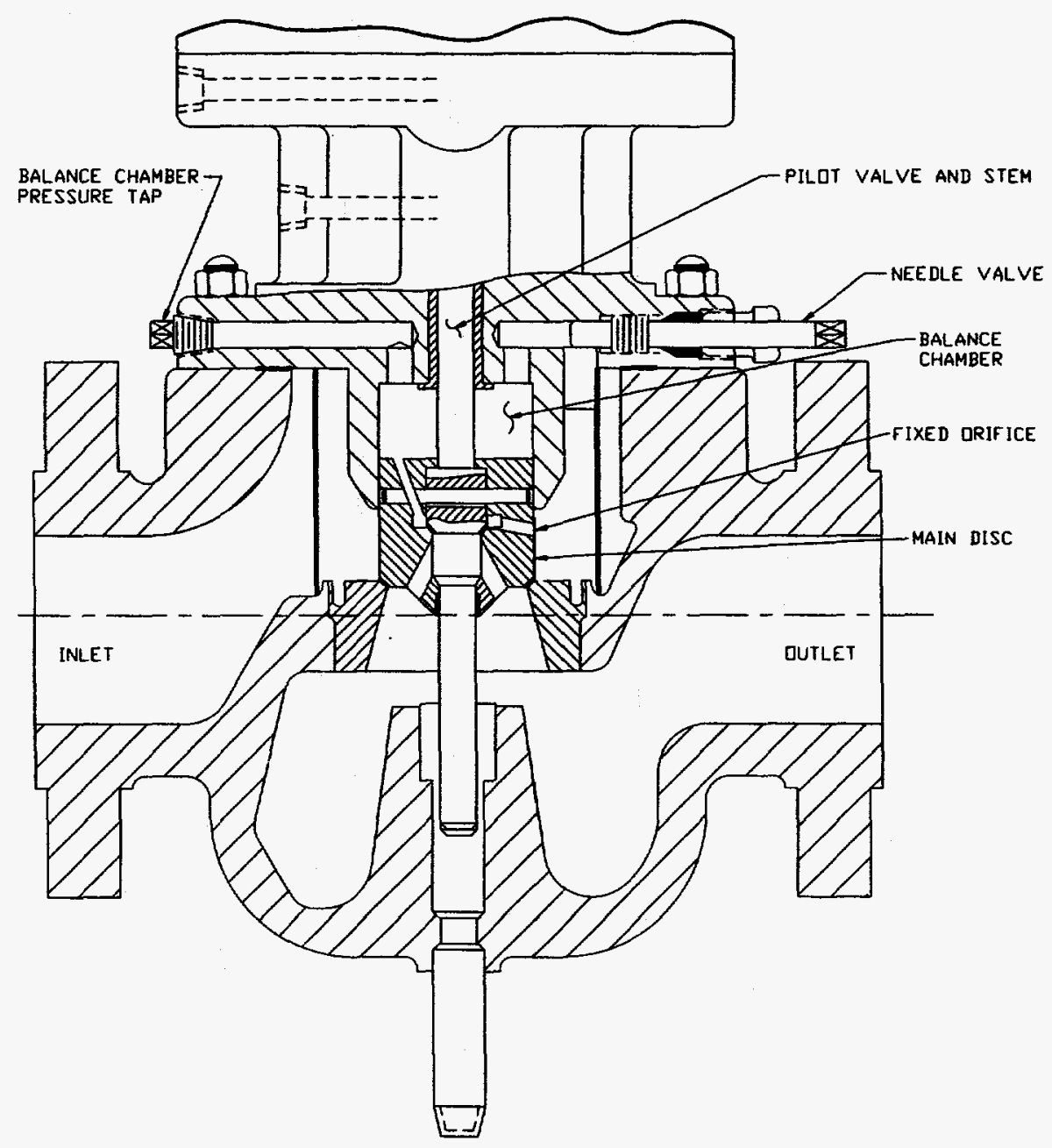

Figure 3.4 T/T valve internals. Reprinted with permission from Electric Power Research Institute, EPRI Nuclear Maintenance Application Center, “Terry Turbine Controls Guide,” NP-6909, 1990 


\subsubsection{Governor Valve}

Two basic governor valve types are available for use in RCIC and AFW turbines: a 2 1/2-in. V-port throttle valve (see Fig 3.5) and a 3-in. venturi seat throttle valve (see Fig. 3.6). Both valves are single seated and pressure

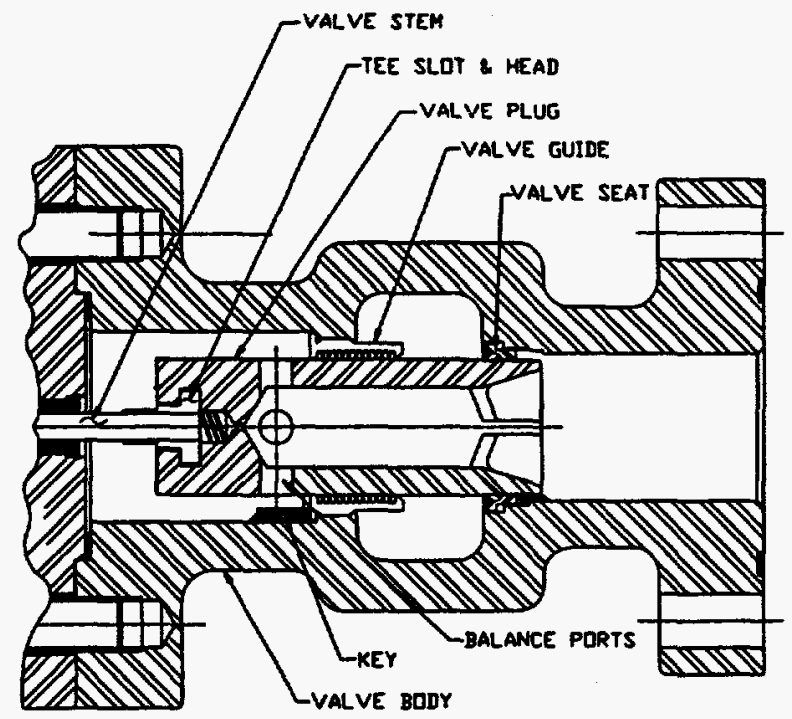

Figure 3.5 2-1/2-in. governor valve. Reprinted with permission from Electric Power Research Institute, EPRI Nuclear Maintenance Application Center, "Terry Turbine Controls Guide," NP-6909, 1990 balanced to reduce the amount of force required to move the valve. The major differences between the valves lie in the configuration of the valve plug, seat, guides, and stem connection.

On the 21/2-in. valve the guides are installed in the valve body before final machining. The guides for the 3-in. valve are actually enclosed in an extension of the valve bonnet. Both the V-port and the venturi seat are welded into the valve body.

The stem connection for the $21 / 2$-in. valve is a T-slot in the plug, with a matching head on the valve stem. The venturi seat valve stem is connected directly to the plug. This type of connection requires that the stem and plug be concentric to prevent binding.

\subsubsection{Turbine}

The turbine (Fig 3.7) is a horizontally split casing, solid wheel design, with the steam inlet and exhaust in the lower half of the casing. This permits maintenance and inspection on the turbine without disturbing piping or turbine-to-pump alignment. The rotor assembly (turbine wheel) is solid, unlike conventional bladed turbines. Small "buckets" are machined into the circumference of the rotor. This allows the turbine to function with moist steam or even water

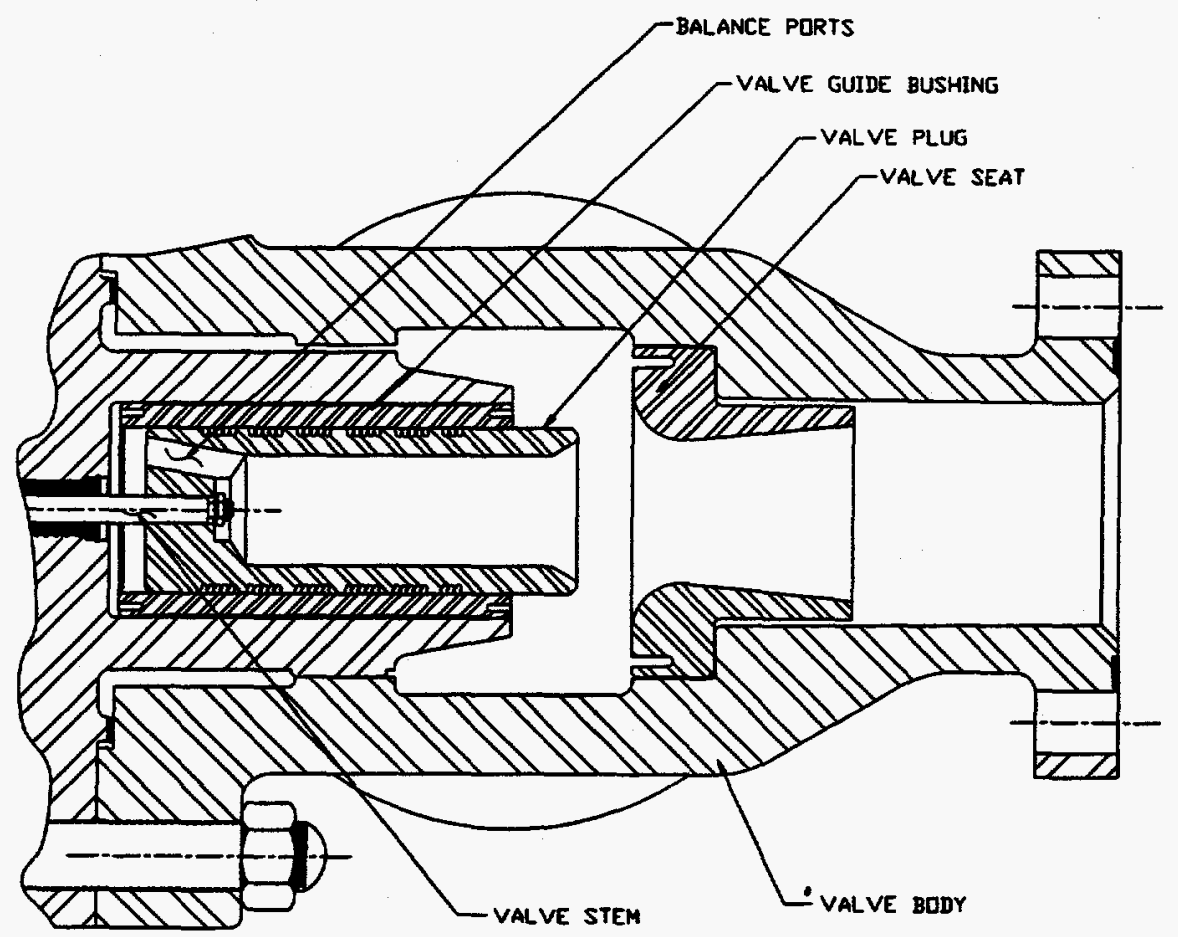

Figure 3.6 3-in. governor valve. Reprinted with permission from Electric Power Research Institute, EPRI Nuclear Maintenance Application Center, "Terry Turbine Controls Guide," NP-6909, 1990 


\section{Equipment}

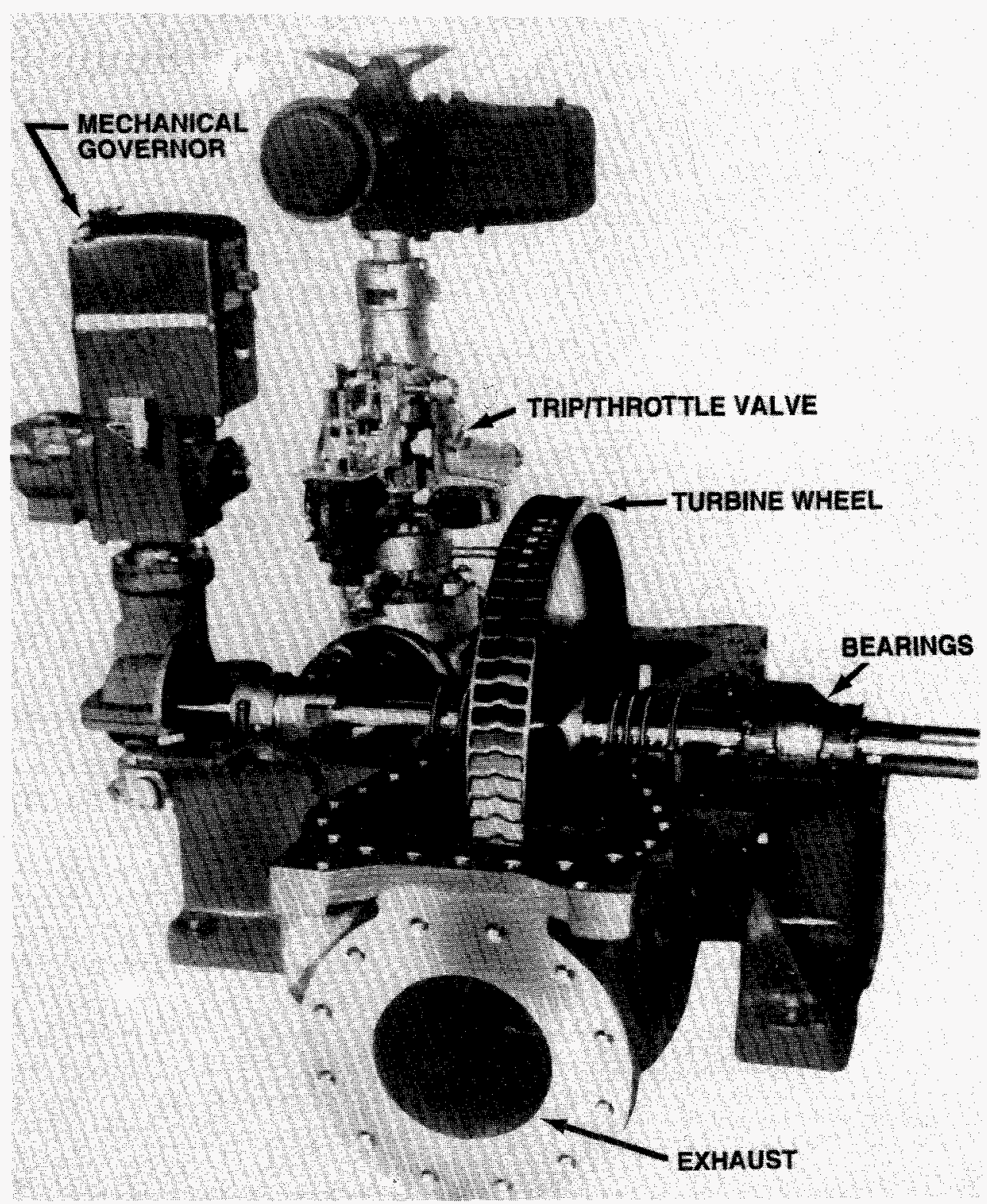

Figure 3.7 Basic turbine configuration. Reprinted with permission from Dresser-Rand Corporation

slugs without destroying the rotor assembly. The shaft seals (glands) are carbon type and are nonlubricated. Leakoff is drained away in separate piping.

The lubricating oil system is operated by a gear-driven pump that operates directly off the turbine (Fig. 3.8). The oil pump supplies oil to the turbine bearings, and on turbines equipped with EGs, it supplies pressure for governor operation also.

\subsubsection{Governor}

The turbine governor system receives the flow controller signal output and converts it into mechanical motion to position the turbine governor valve to maintain the turbine at the referenced speed (Fig. 3.1). The turbine governor system is calibrated so maximum and minimum flow requirements are met.

\subsubsection{Overspeed Trip Mechanism}

The OST mechanism (Fig. 3.9) is composed of three basic components: (1) a speed-sensing device, (2) the trip linkage, and (3) the T/T valve (see Sect. 3.1.2). The speedsensing device is attached to or integral with the turbine shaft and is eccentrically weighted. The centrifugal force generated by turbine shaft speeds in excess of predetermined limits will cause the weight to move radially outward, striking a tappet. Tappet movement causes the 


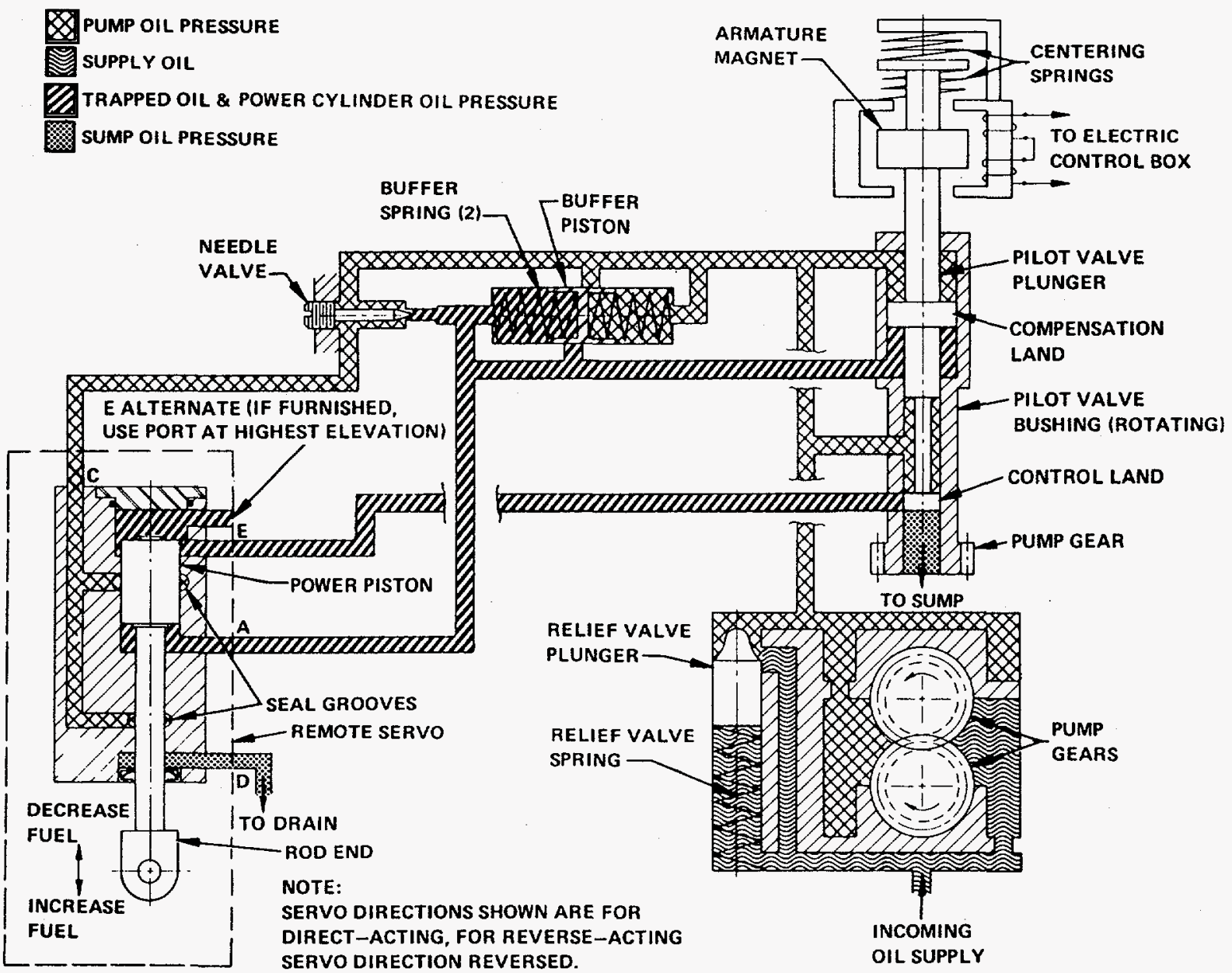

Figure 3.8 Electronic governor remote (EGR) schematic. Reprinted with permission from Woodward Governor Company

spring-loaded trip linkage to actuate and thus close the $\mathrm{T} / \mathrm{T}$ valve.

Once the valve trips, it must be manually reset for turbine operation to resume. First the connecting rod (Fig. 3.9) must be reset. This requires that an operator grab the connecting rod and pull it toward the T/T valve against the trip spring force. At this time the operator must also verify that the trip tappet has dropped down to its normal position, where it will rest against the flat face of the head lever. The tension on the connecting rod is then released. The $T / T$ valve must then be cranked closed, using the handwheel or the motor operator, to relatch the trip hook and latch lever. Then the valve must be opened, manually or electrically, to permit flow through the valve.

As an option, some turbines are equipped with an electronic overspeed sensing and trip device. The signal from the frequency to voltage converter is also the input to a switch located in the tachometer circuitry. When turbine shaft speed exceeds a preset value (which is lower than the mechanical OST set point), relay contacts close. This sends a trip signal to the trip solenoid, which is located on the $T / T$ valve, resulting in a turbine trip. The advantage to the electronic OST is the ability to remotely reset the trip. This cannot be done with the mechanical OST device.

Many facilities removed the electronic OST devices because an electronic OST was immediately followed by a mechanical OST. The time difference between the electronic OST and a decrease in turbine speed was not small enough to prevent the mechanical OST. Therefore, the advantage of a remote OST reset was not realized. The addition of OST circuitry added the potential for inadvertent tripping without increasing safety, reliability, or convenience. Reliability of the turbine was thus potentially compromised without any apparent benefit. On the other hand, some utilities increased the trip point on the electronic OST from 110 to $125 \%$ of normal operating speed and have enjoyed successful and reliable operation of the device. At these plants, raising the electronic OST set point minimized trips caused by startup transients. 


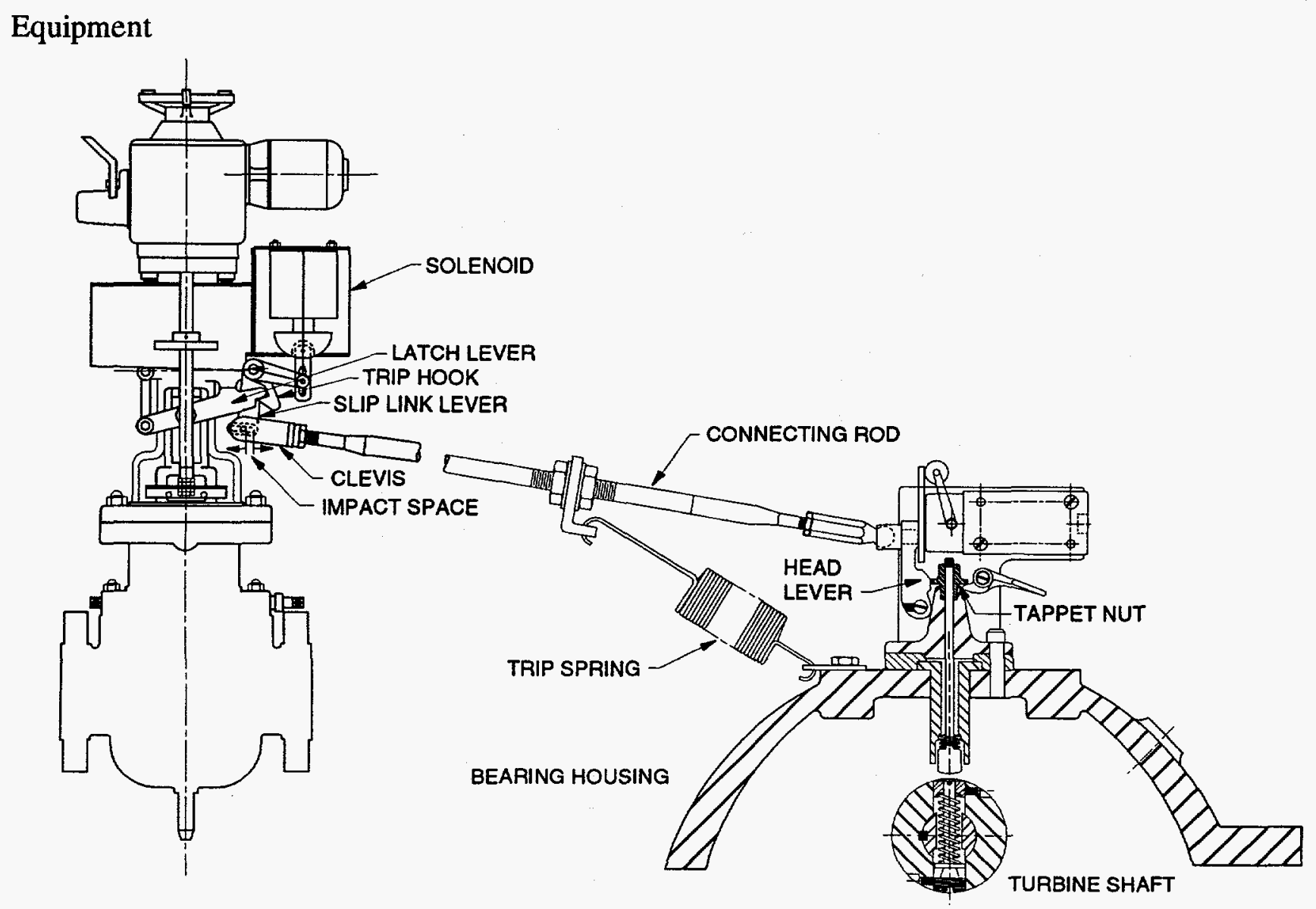

MECHANICAL OVERSPEED TAIP MECHANISM

Figure 3.9 Mechanical OST mechanism

\subsection{HPCI Turbine-Operation Overview}

On initiation of the HPCI system, the motor-driven auxiliary oil pump for the turbine forced feed lubrication system starts simultaneously with the opening of the motoroperated steam line shut-off valve (supplied by others), located upstream of the hydraulically operated turbine stop valve. As oil pressure is established in the turbine hydraulic system, the multistage governor valves will go to the "full open" position closely followed by the opening of the turbine stop valve.

At essentially the same time as the turbine stop valve leaves its seat from the "fully closed" position, the turbine governor system "ramp generator" function is initiated by the mechanical movement of the valve stem actuating a valve position indicator switch.

The "ramp" generator will ramp from an "idle" turbine speed set point to the rated "high" turbine speed set point or to some speed relative to the output signal from the flow controller, which results in satisfactory "pump flow" demand.

At almost the same time that the turbine starts to roll, the turbine governing system (sensing speed) actuates the governor valves, via remote hydraulic servomotor and oil relay, to a position relative to the ramp generator signal converter output signal demand. Thus, this action provides acceleration control without OST through the ramp rate of the ramp generator.

As flow is developed and reaches the set point of the flow controller, the flow controller output signal to the turbine governor will adjust to where constant rated pump flow is obtained.

As pump discharge and steam inlet pressure change with a variable reactor pressure range, an appropriate controller output signal will be sent to the turbine to maintain constant steady state pump flow. 
The system consists of the following major components, similar to the AFW/RCIC turbine systems:

- SAV,

- stop valve,

- governor valve,

- turbine,

- governor, and

- OST mechanism.

\subsubsection{Steam Admission Valve}

The SAV performs the same function in this system as it does in the AFW/RCIC systems: opening to admit steam to the governor valve for a turbine start. See Sect. 3.1.1 for more information on this valve.

\subsubsection{Stop Valve}

The Terry Corporation Model CS/CCS turbine stop valve (Fig. 3.10) is an inverted, oil-operated, semibalanced globe-type valve. Hydraulic pressure in the hydraulic cylinder (part 15) is used to open the valve, and spring force and steam pressure close the valve when the hydraulic pressure is dumped through a pilot valve mounted on the hydraulic cylinder.

The stop valve is equipped with limit switches for open/ close indication and ramp initiation and with an internal steam strainer on all but some of the oldest models.

During a typical opening cycle (see Fig. 3.10), an oil signal pressure of $\sim 20 \mathrm{psig}$ at connection (26) will compress the spring (22) and shift the relay valve piston (18) to close the drain opening in body (19), and then open a passage for the main oil supply through an inlet connection (21), around relief in the piston (18), and into the hydraulic cylinder (15). [Oil entrapped in the spring case area (22) is discharged through the relay piston (18) to the drain line.] An orifice in the relay body will admit $\sim 9 \mathrm{gal} / \mathrm{min}$ of oil into the hydraulic cylinder (15), which limits the valve opening time. A drain-off bypass flow control (28) is provided but has been determined unnecessary for timing purposes and is normally closed or removed with the piping plugged.

The hydraulic cylinder piston rod is connected with a split coupling (36) to the stop valve stem (45). During the first $1 / 4$ in. of stem stroke, the pilot in the disk opens, and the balancing chamber is evacuated to the downstream side of the valve chest. When the pilot valve begins to lift the main disk, the pressure in the balancing chamber has reduced to a minimum value, partially balancing the main disk. For the remaining $2.5 \mathrm{in}$. of stroke, the flow area between the disk (47) and seat (46) increases. Switch (11) left is tripped when the valve is in full open position.

When closing, the oil signal pressure at (26) drops to -12 psig; the spring (22) exerts sufficient force to shift the relay valve piston (18). The open passage of the main oil supply is first cut off, and then additional piston movement opens the oil discharge port between the hydraulic cylinder (15) and the oil discharge connection. The high-pressure oil discharge drives the relay piston to its relaxed position. A compression spring in the hydraulic cylinder (15) actuates closure of the valve proper and forces the oil from the main cylinder through the dump port. The pilot valve (45) seats in the disk (47), which seats on body seat (46) to provide a tight seal. Internal pressure acting on the disk (47) assists the hydraulic operator unit in tight seating. Switch (11) right is tripped when the valve is in full-closed position.

\subsubsection{Governor Valve}

The governor valve for the HPCI turbine is different in configuration, but not function, from the governor valve for the AFW/RCIC turbine. The governor valve for the HPCI turbine consists of five ports (hence, the term multiport), which open in sequence (see Fig. 3.11). This allows more control over the HPCI turbine, which is larger than the GS2 series used for the AFW/RCIC. In function, however, the principle of operation is the same, with the governor valves opening on turbine start to control the amount of steam admitted to the turbine.

\subsubsection{Turbine}

The majority of the HPCI turbines in service were manufactured by the Terry Corporation (currently a division of Dresser Rand Corporation), and are models CS or CCS turbines. These turbines are similar in construction to the GS-2N turbines used extensively in AFW/RCIC systems. However, these turbines are quite a bit larger $(-5500 \mathrm{hp}$ vs $2000 \mathrm{hp}$ for the GS-2 model) and more powerful. Like the GS-2 turbines, the steam supply can range in pressure from 150 to $1100 \mathrm{psi}$. Turbine configuration, however, remains similar and is covered in Sect. 3.1.4.

\subsubsection{Governor}

The Woodward EG governor used on the HPCI turbine is almost identical in composition and function to the type used on AFW/RCIC systems. The description of governor configuration and operation is detailed in Sect. 3.1.5.2. 
* CLOCKWISE = DECREASE BALANCE CHAMBER PRESSURE COUNTER-CLOCKWISE = INCREASE BALANCE CHAMBER PRESSURE

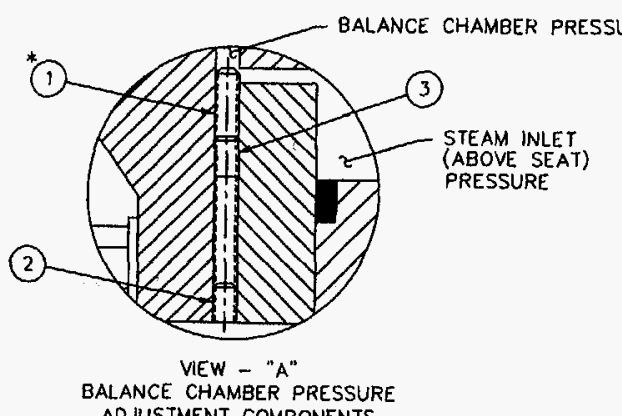

AD UUSTMENT CONPONENTS

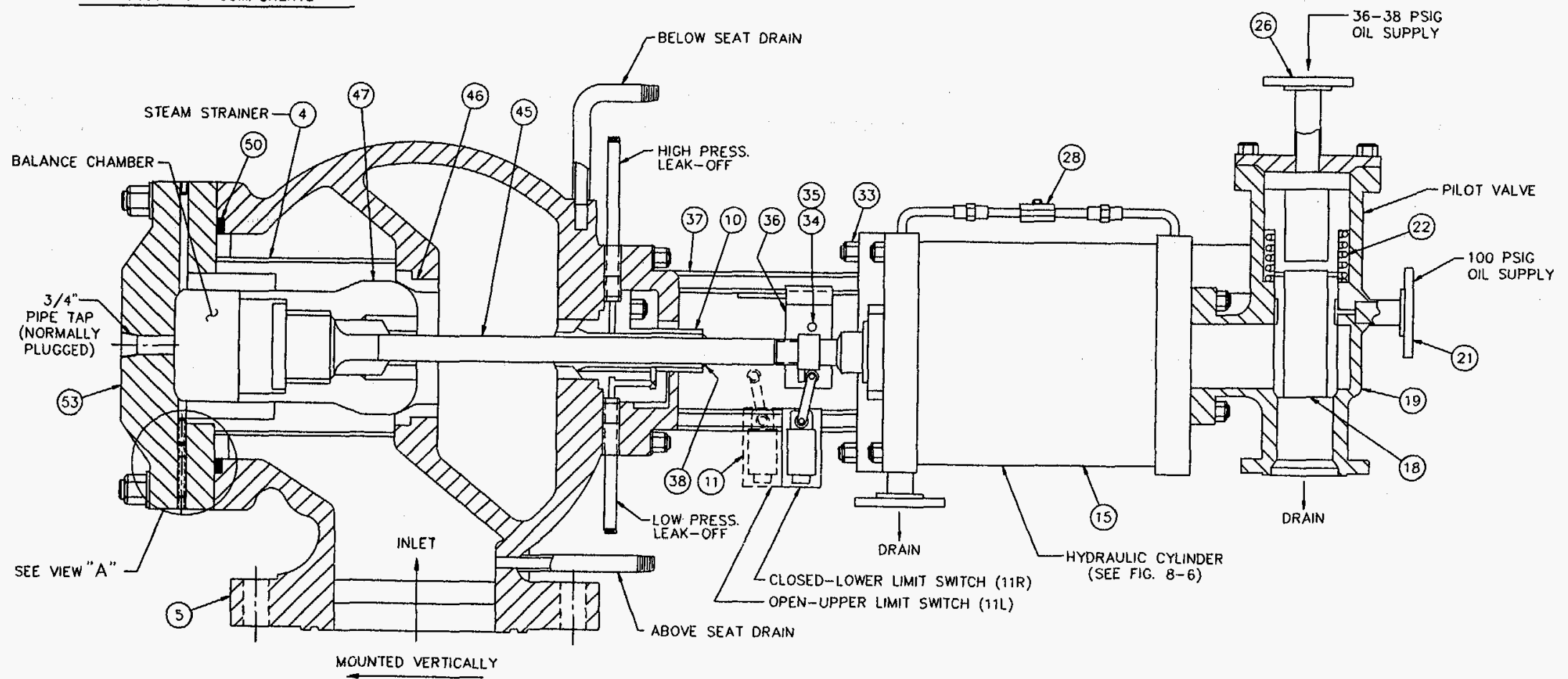

Figure 3.10 HPCI stop valve. Reprinted with permission from Electric Power Research Institute, EPRI Nuclear Maintenance Application Center, "Terry Turbine Controls Guide," NP-6909, 1990 


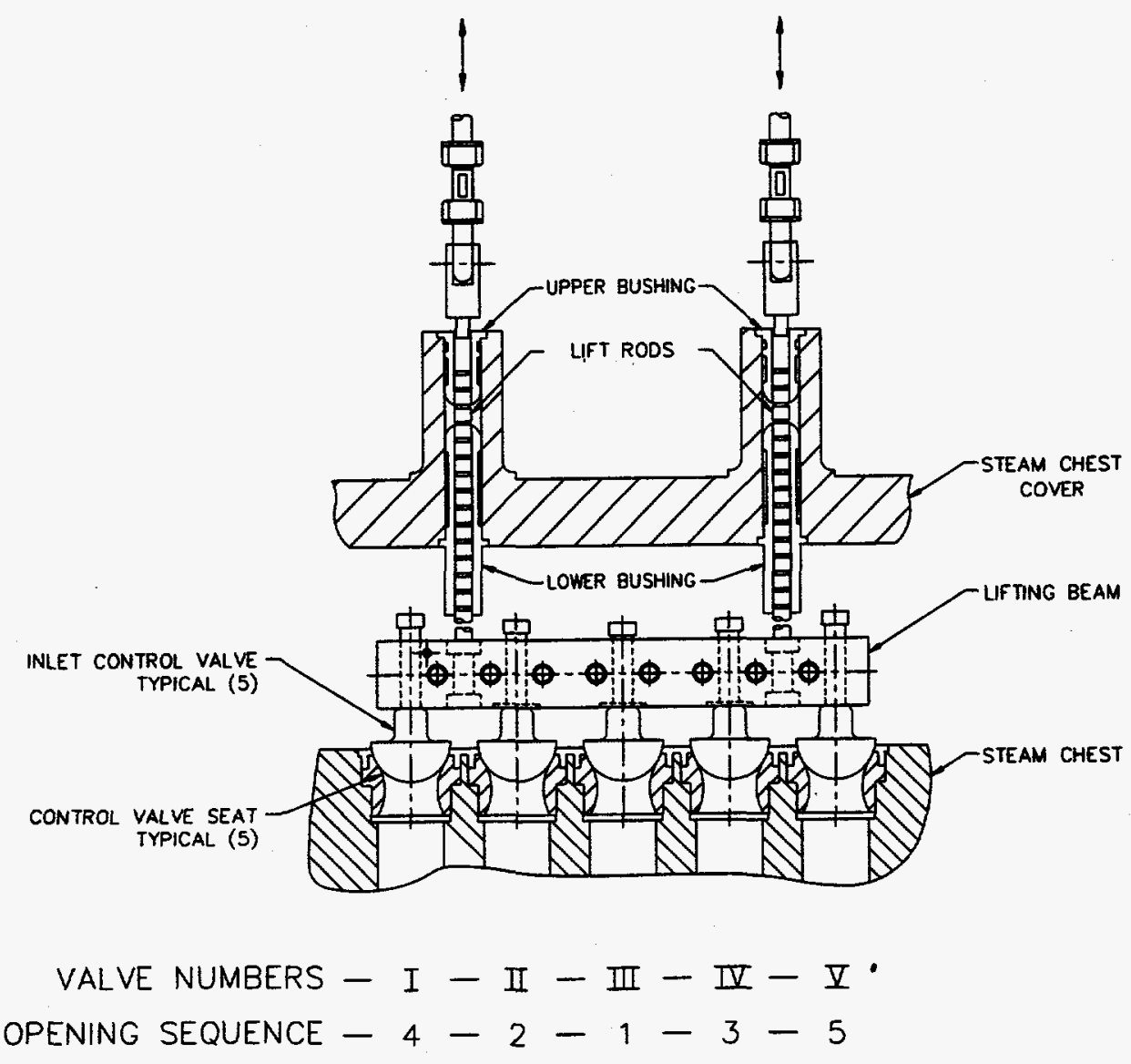

Figure 3.11 Multiport HPCI governor valve. Reprinted with permission from Electric Power Research Institute, EPRI Nuclear Maintenance Application Center, "Terry Turbine Controls Guide," NP-6909, 1990

\subsubsection{Overspeed Trip Mechanism}

The OST system for HPCI turbines (see Fig. 3.12) resembles the trip mechanism for the AFW/RCIC turbines in that there is a shaft-mounted trip pin, a trip mechanism, and a valve that isolates steam to the turbine. However, for the HPCI turbine the trip mechanism is replaced by a hydraulic trip valve assembly, and the T/T valve is replaced by the turbine stop valve.

The shaft-mounted trip pin resembles the type used for the AFW/RCIC turbine. It is shaft-mounted and eccentrically weighted, moving outward to strike the trip tappet when the centrifugal force generated by the rotating turbine shaft exceeds a preset limit. At this speed the trip pin moves radially outward, having overcome the force of the spring that normally holds the trip pin in position, and strikes the trip tappet of the hydraulic trip valve.

The hydraulic trip valve assembly allows the pressurized oil, which holds the stop valve open, to drain to the sump. This will happen as a result of the trip tappet being struck by the shaft-mounted trip pin. When the oil pressure is reduced, a spring in the stop valve forces the piston closed. Unlike the mechanical linkage of the AFW/RCIC turbines, the HPCI OST mechanism will automatically reset after a predetermined amount of time has elapsed.

Limit switches and remote lights indicate whether the stop valve is open, shut, or in an intermediate position. 


\begin{tabular}{|l|l|c|l|}
\hline ITEM & DESCRIPTION & ITEM & DESCRIPTION \\
\hline 1 & CAP SCREW & 13 & TAPPET ASS'Y. \\
\hline 2 & SET SCREW & 14 & PEDASTAL CAP \\
\hline 3 & RESET KNOB & 15 & SO. KEY \\
\hline 4 & SPRING ADJ. SLEEVE & 16 & SET SCREW \\
\hline 5 & HEX JAM NUT & 17 & EMERG. WEIGHT ADU. SCREW \\
\hline 6 & CAP SCREW & 18 & EMERG. TRIP WEIGHT \\
\hline 7 & EMERC. VALVE BODY CAP & 19 & TURBINE SHAFT \\
\hline 8 & SPRING & 20 & EMERG. TRIP DISC \\
\hline 9 & PIPE PLUG & 21 & EMERG. WEIGHT SPRING \\
\hline 10 & COTTER PIN & 22 & EMERG. SPRING ADJ. SCREW \\
\hline 11 & PISTON & 23 & GASKET \\
\hline 12 & VALVE BOOY & & \\
\hline
\end{tabular}

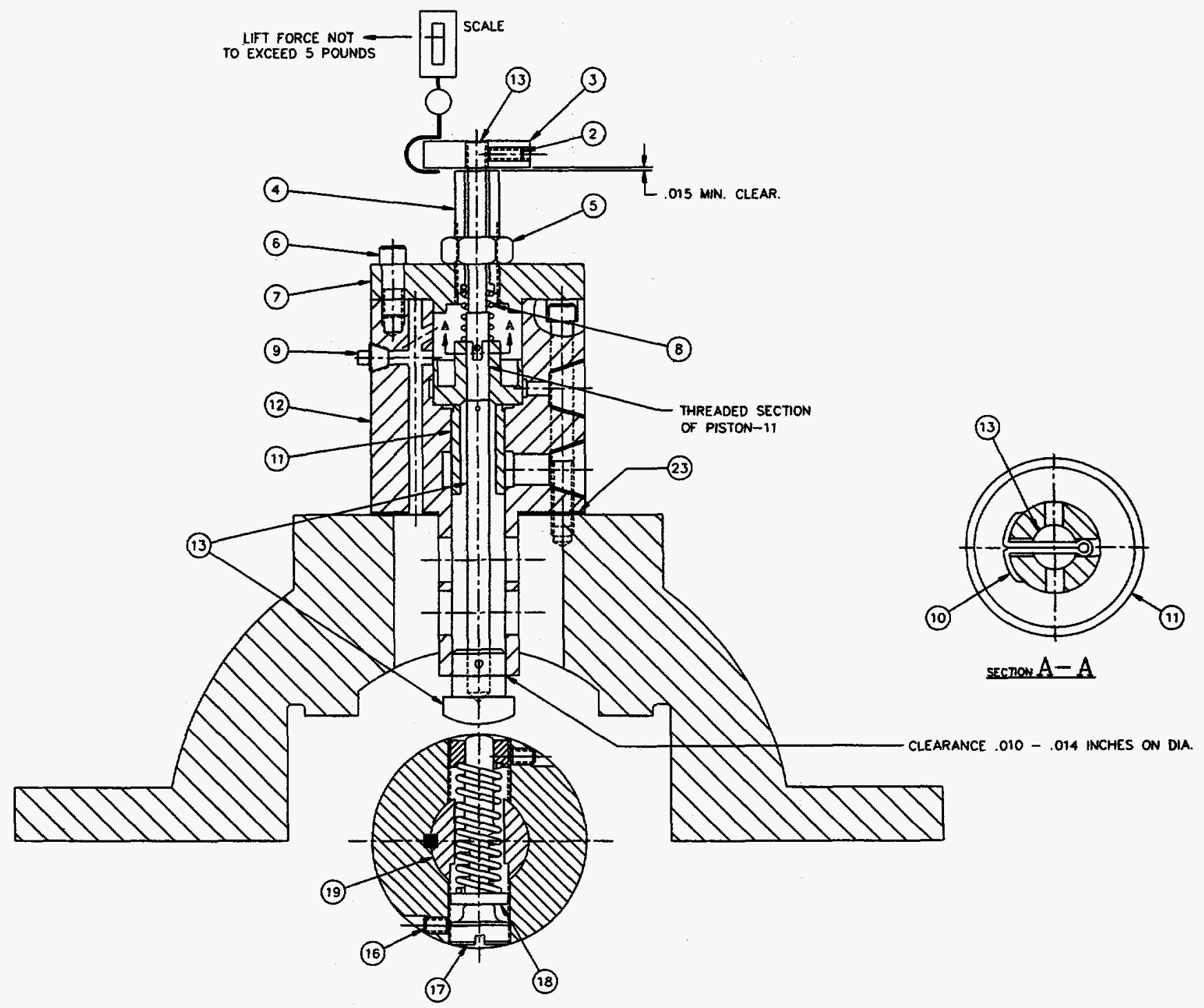

Figure 3.12 HPCI trip valve assembly. Reprinted with permission from Electric Power Research Institute, EPRI Nuclear Maintenance Application Center, “Terry Turbine Controls Guide,” NP-6909, 1990 


\section{Analysis of Operational Data}

\subsection{Introduction}

Historical failure data were gathered from LERs and the NPRDS and placed in a data base. The data collected included the following fields:

- reporting site,

- description narrative,

- cause narrative,

- corrective action narrative

- date of failure start, and

- method of failure detection.

The data were then examined to determine events that had been recorded in both NPRDS and on an LER. Duplicate events were then removed from the data base. At this point fields were added to allow the addition of codes to permit categorization:

1. Major component group — the six major components:

- SAV

- $\mathrm{T} / \mathrm{T}$

- governor valve

- turbine

- governor

- OST
2. Subcomponent-the piece part or subcomponent actually involved in the failure.

3. Cause - a code assigned to the failure based on a review of the description narrative, independent of the cause reported by the utility.

The resulting data base had 375 individual failures, ranging in time from 1984 to 1991. Each event was then reviewed, analyzed, and categorized.

\subsection{Data Analysis}

The failure records were reviewed and characterized by component group, method of detection, plant age at failure, calendar year, and affected plant. Summaries of the results of these characterizations follow.

\subsubsection{Failure Data Analysis by Component Group}

The initial evaluation of failures resulted in seven categories: five of the six major categories plus categories for reports of turbine failures that were caused by associated devices (see Fig. 4.1). Those failures attributed directly to

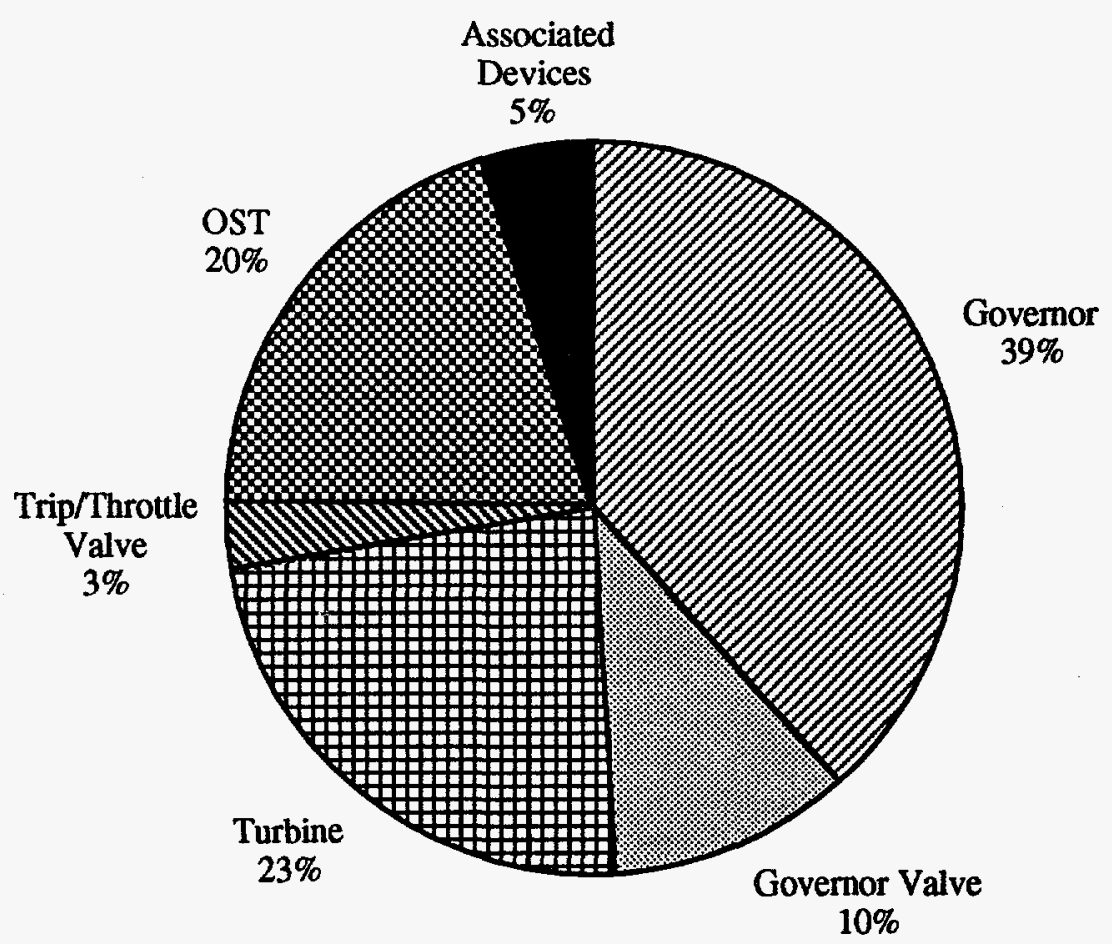

Figure 4.1 Percentage of total failures by component 
Analysis

the SAV have been included with the failures of associated devices. The data did not consistently indicate when a failure could be attributed to the SAV because these failures can be reported with either the main steam system or the AFW system. Accounting for all failures of the SAV would require identifying the component identification number for the SAV at each plant. Then all valve failures in both the main steam system and the AFW system would have to be evaluated to find failures of these particular valves. An effort of this magnitude was not deemed justifiable for this report. The failures caused by associated devices were random in nature and did not show any repeatable pattern. Therefore, they were omitted from the rest of the report.

Evaluation of the data after categorizing by component group reveals the governor as the single component that fails most often, followed by the turbine, mechanical OST mechanism, and the governor valve. Component-specific details are discussed in Sect. 4.3.

\subsubsection{Method of Detection}

The failure records were reviewed to determine how failures were discovered. The following categories were established:

- Demand failures-Failures that occur when the system is called on to function in a nontest situation.
- Programmatic testing failures-Failures that occur during surveillance, postmaintenance testing, or periodic operability testing. Also included are instances where the turbine may not have failed to operate, but had been declared inoperable due to unacceptable oil samples.

- Inspection-Category that includes both in-service inspection and any special inspection that indicated unacceptable performance.

- Maintenance-Any unacceptable conditions discovered during preventive or corrective maintenance.

- Observation-Those unacceptable conditions that are observed as part of an individual's normal job. This includes operators, system engineers, or any other person who periodically examines the turbine for visible degradation or breakage.

The data indicate that the highest percentages of failures are detected during scheduled (programmatic) testing (55\%) (see Fig. 4.2). This trend is consistent for each year examined. The second most prevalent method of detection was a demand failure (19\%), followed by the combination of routine and incidental observation (13\%).

\subsubsection{Programmatic Testing Failures}

The majority of the failures examined were discovered by programmatic means. Programmatic discoveries

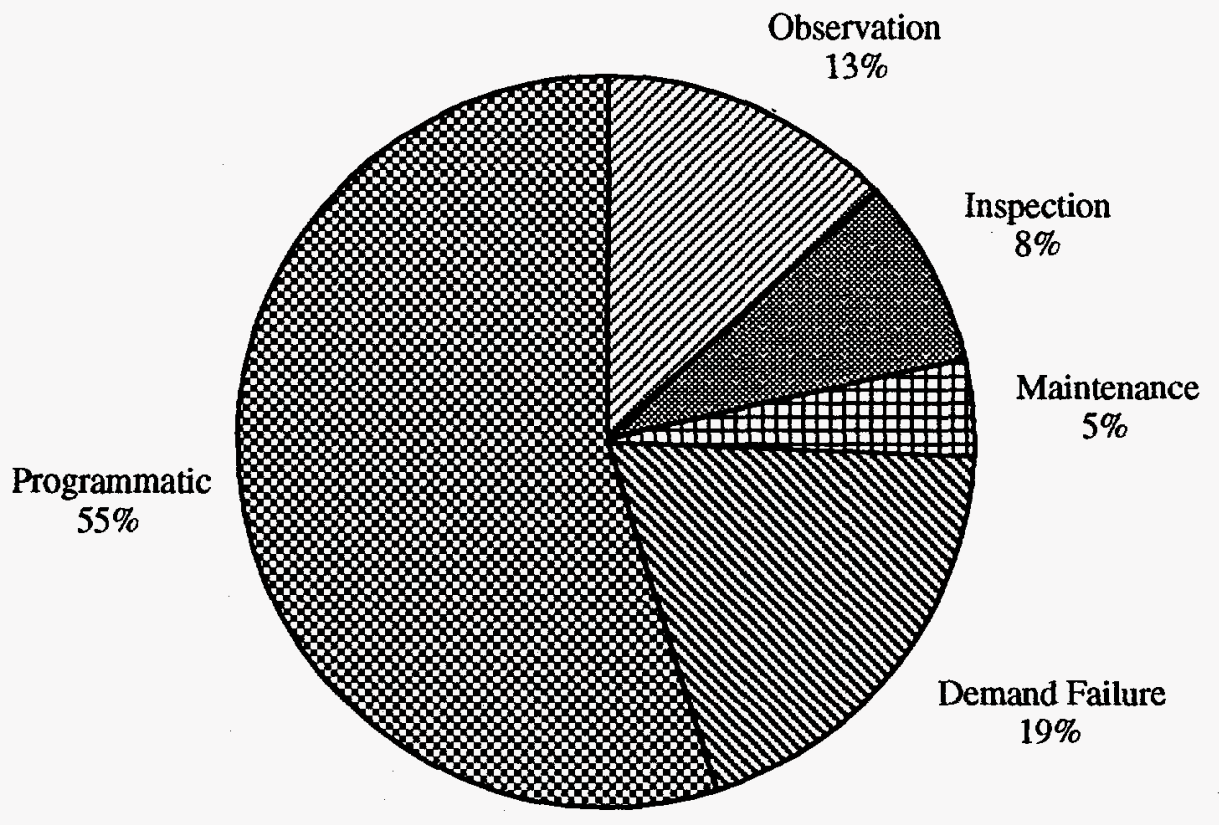

Figure 4.2 Failure by method of detection 
outnumbered demand discoveries by almost a factor of 4 to 1. Programmatic discoveries include routine surveillance testing, in-service inspection, and routine observation by persons such as system engineers who walk down systems on a regular basis.

Obviously, it is preferable to discover equipment degradation by programmatic means rather than by demand failures. Since 1984 there has been a general increase in the percentage of failures discovered by programmatic means (Fig. 4.3). This indicates that utility maintenance/ monitoring programs may be beginning to improve turbine availability. The number of turbine degradations and the methods of discovery should be monitored in the future to verify the existence of trends relative to both a decrease in the total number of failures and an increase in the percentage of problems discovered by programmatic means.

\subsubsection{Demand Failures}

Roughly $20 \%$ of the failures were detected during demand conditions. Note in Fig. 4.4 that demand failures between 1988 to 1991 were approximately half of those reported between 1985 and 1987. While this decrease is a good trend, the fact that $20 \%$ of the turbine failures are discovered when the turbine is called upon to perform a safetyrelated function is significant.
Figure 4.5 indicates that the fraction of all failures that were discovered on demand was less between 1988 to 1991 than between 1985 to 1987.

\subsubsection{Plant Age at Failure}

Further examination of the data indicated that the maximum number of failures per year occurred at a turbine age of between 10 and 15 years. This means that there were more failures of turbines in this age bracket than of turbines at any other age (Fig. 4.6). This information was obtained by normalizing the data base around the age of the turbine at the time of the reported failure.

The data were normalized by considering the turbine age at the time of the failure and dividing the number of failures for a particular age turbine by the number of turbines of that age that could have failed.

\subsubsection{Plant Distribution}

Examination on a failures per plant basis reveals that a relatively small number of plants contribute the majority of the failures. Examination of Fig. 4.7 reveals that only 7 of 86 plants contribute $25 \%$ of the failures, and only 18 of 86 plants contribute 188 of the 375 failures $(-50 \%)$. The

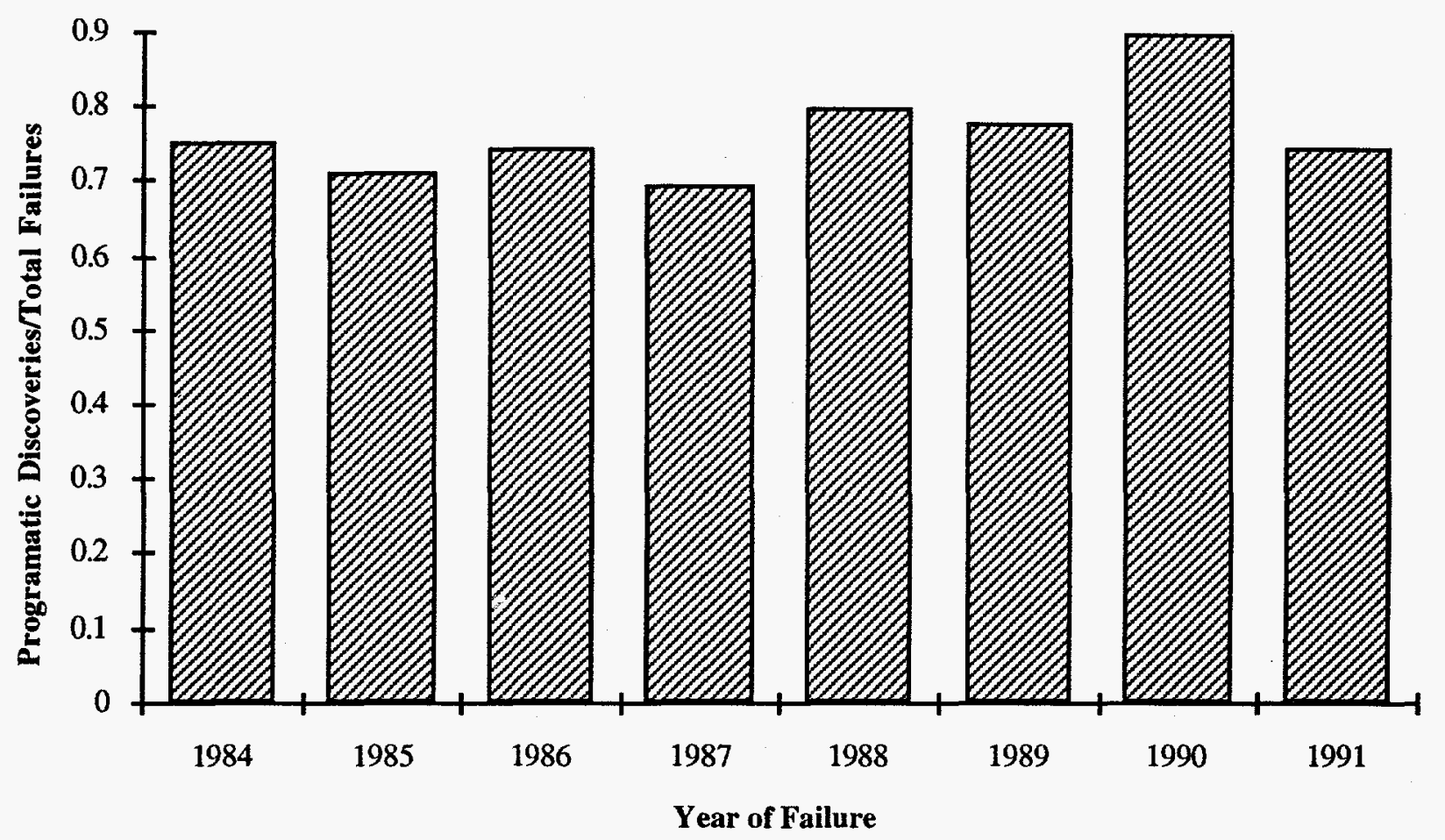

Figure 4.3 Failures discovered programatically 
reader is cautioned against drawing conclusions based on this limited amount of data. Many variables could potentially contribute to these figures. The quality of reporting by individual utilities varies from plant to plant. Reporting may even change at the same plant with changes in personnel and reporting practices. There have also been instances where failures accumulated against a particular plant while the vendor went through an iterative process of subcomponent redesign and replacement.

\subsubsection{Failure Data Analysis by Year}

Analysis of the failure data by year reveals no definitive trends that can be determined from a graphic representation of the failure data. A discussion of component failures by year and failures by method of detection and year follow.

\subsubsection{Failures by Component and Year}

As was previously mentioned, governor failures typically dominate single component failures (Fig. 4.8). Note that the relationship between failures for all components is relatively stable for the years examined.

Examination of the data does not reveal any reason for the apparent rise in the number of failures occurring in $\mathbf{1 9 9 0 .}$
Apparently, no particular component had an increased failure rate, nor was there any change in reporting requirements that could be determined. It is possible that programmatic discoveries could have a significant effect on this number (Sect. 4.2.5.2). Failures by component and year are tabulated in Table 4.1.

\subsubsection{Failures by Method of Detection and Year}

As was previously noted, 1990 saw an increase in the number of failures across all component categories (Fig. 4.8). While no particular component accounts for this increase, examination of the method of discovery indicates a marked increase in the number of failures discovered by programmatic methods (testing) (Fig. 4.9). These data are given in Table 4.2. This increase, however, does not negate the fact that a large percentage of the failures are still found during demand events.

\subsection{Equipment-Specific Results}

\subsubsection{Steam Admission Valve}

The historical failure data do not show specific failures for the SAV. Most often failures of the SAV are not related to

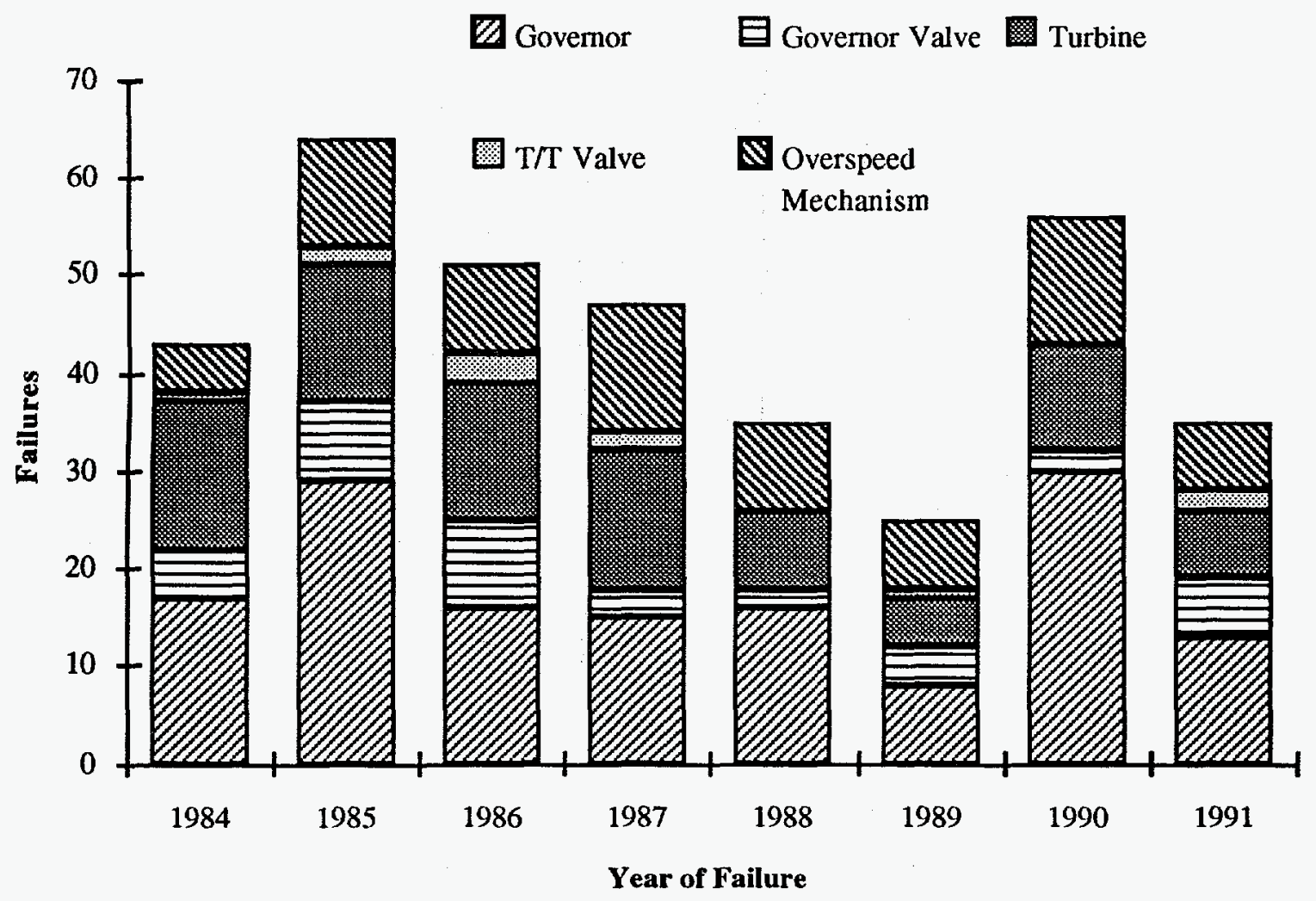

Figure 4.8 Failures per component per year 
Table 4.1 Summary of failures by component and year

\begin{tabular}{rrrrrrrrrr}
\hline & \multicolumn{1}{c}{ Component } \\
\cline { 2 - 9 } Year & Governor & $\begin{array}{c}\text { Governor } \\
\text { valve }\end{array}$ & Turbine & OST & $\begin{array}{c}\text { T/T } \\
\text { valve }\end{array}$ & Controls & $\begin{array}{c}\text { Other/ } \\
\text { unknown }\end{array}$ & Total \\
\hline 1984 & 17 & 5 & 15 & 5 & 1 & 0 & 1 & 44 \\
1985 & 29 & 8 & 14 & 11 & 2 & 5 & 0 & 69 \\
1986 & 16 & 9 & 14 & 9 & 3 & 0 & 3 & 54 \\
1987 & 15 & 3 & 14 & 13 & 2 & 0 & 2 & 49 \\
1988 & 16 & 2 & 8 & 9 & 0 & 1 & 3 & 39 \\
1989 & 8 & 4 & 5 & 7 & 1 & 1 & 1 & 27 \\
1990 & 30 & 2 & 11 & 13 & 0 & 1 & 1 & 58 \\
1991 & 13 & 6 & 7 & 7 & 2 & 0 & 0 & 35 \\
Total & 144 & 39 & 88 & 74 & 11 & 8 & 11 & 375 \\
\hline
\end{tabular}

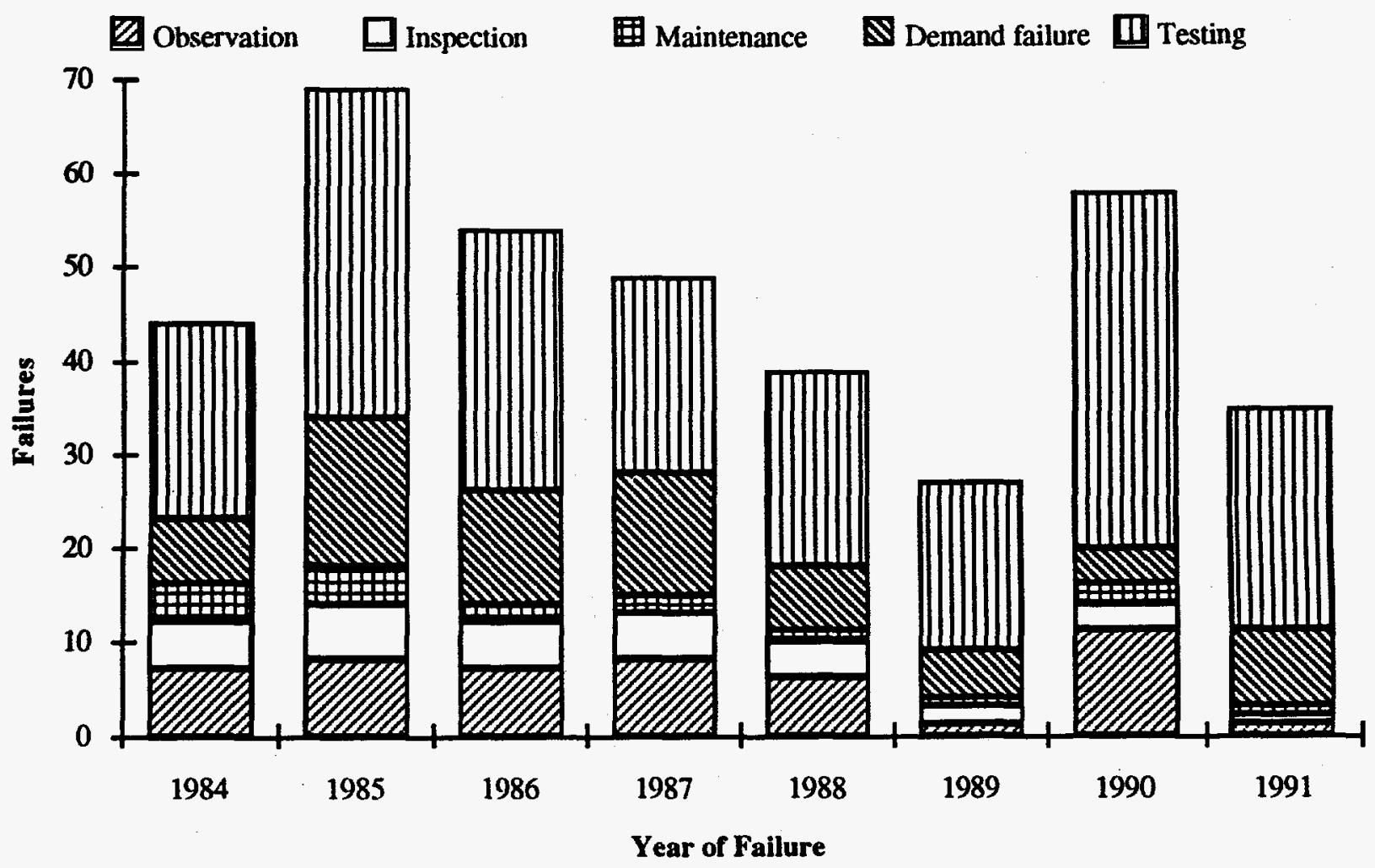

Figure 4.9 Number of failures per year by method of discovery

the turbine in failure reporting. To discover these failures would require identifying the SAV for each facility, tabulating all failures for that valve, and subsequently identifying those that could have or did impact turbine operation. However, failures associated with the SAV are often manifested as unexplained OSTs. This type of failure is covered in Sect. 3.1.1.3.

\subsubsection{Turbine}

Of the 88 problems associated with the turbine, $-40 \%$ of the failures examined were traceable to the lubricating oil system or to subcomponents that are directly dependent on the lubricating oil system (bearings) to maintain function. Bearing failures were the most prevalent (18) of failures 
Table 4.2 Summary of failures by method of detection

\begin{tabular}{|c|c|c|c|c|c|c|c|c|c|}
\hline \multirow[b]{2}{*}{ Method of discovery } & \multicolumn{8}{|c|}{ Year } & \multirow[b]{2}{*}{ Total } \\
\hline & 1984 & 1985 & 1986 & 1987 & 1988 & 1989 & 1990 & 1991 & \\
\hline Observation & 7 & 8 & 7 & 8 & 6 & 1 & 11 & 1 & 49 \\
\hline Inspection & 5 & 6 & 5 & 5 & 4 & 2 & 3 & 1 & 31 \\
\hline Maintenance & 4 & 4 & 2 & 2 & 1 & 1 & 2 & 1 & 17 \\
\hline Demand failure & 7 & 16 & 12 & 13 & 7 & 5 & 4 & 8 & 72 \\
\hline Testing & 21 & 35 & 28 & 21 & 21 & 18 & 38 & 24 & 206 \\
\hline Total by year & 44 & 69 & 54 & 49 & 39 & 27 & 58 & 35 & 375 \\
\hline
\end{tabular}

with the most significant consequences and are most often discovered by high-bearing temperatures as monitored by thermocouples installed in the bearing housings.

The data examined did not reveal any turbine trips due to failed bearings. The data indicate a decrease in the number of bearing failures per year since 1986. This trend is consistent with the pattern of failures for all subcomponents.

The other $60 \%$ of problems associated with the turbine had the potential to affect turbine operation on a long-term basis but did not jeopardize the performance of the safetyrelated function at the time of failure discovery. Such instances include minor oil leaks, gasket leaks, and lube oil sight glass leaks. While such instances total a greater num- ber than occurrences like governor valve failures (Fig. 4.1), their significance relative to turbine operability makes them less important than other failures.

The distribution of turbine-related failures is provided in Fig. 4.10 and Table 4.3.

\subsubsection{Governor Valve}

While more failures were reported for the turbine than the governor valve, the failures associated with the governor valve must be examined in light of the potential to affect turbine operation, not just the volume of failures. The distribution of causes for governor valve failures is provided in Fig. 4.11 and Table 4.4.

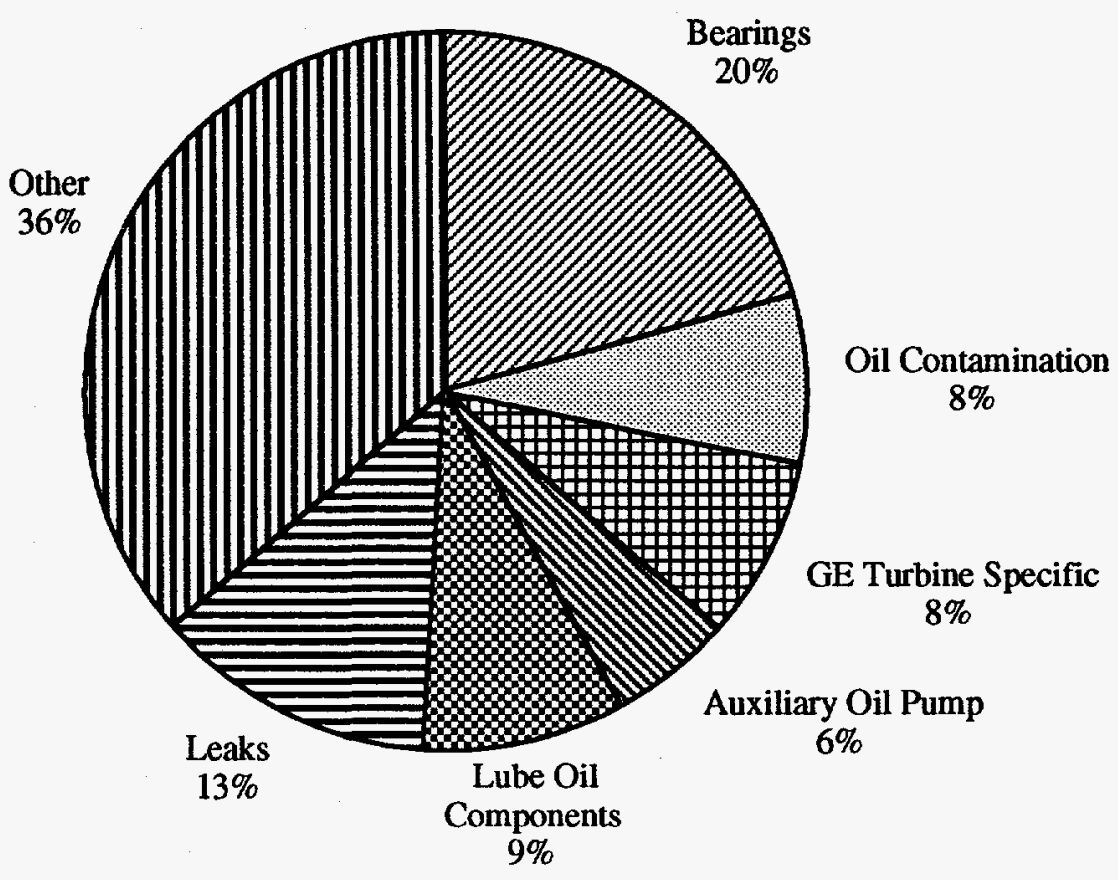

Figure 4.10 Breakdown of turbine failures 
Table 4.3 Breakdown of reported turbine failures

\begin{tabular}{lrrrrrrrrrr}
\hline & \multicolumn{10}{c}{ Year } \\
\cline { 2 - 9 } Subcomponent & $\mathbf{1 9 8 4}$ & $\mathbf{1 9 8 5}$ & $\mathbf{1 9 8 6}$ & $\mathbf{1 9 8 7}$ & $\mathbf{1 9 8 8}$ & $\mathbf{1 9 8 9}$ & $\mathbf{1 9 9 0}$ & $\mathbf{1 9 9 1}$ & Total \\
\hline Bearings & 0 & 3 & 7 & 5 & 1 & 1 & 0 & 1 & 18 \\
Oil contamination & 3 & 0 & 0 & 0 & 2 & 0 & 1 & 1 & 7 \\
Leaks & 1 & 2 & 0 & 1 & 1 & 0 & 2 & 4 & 11 \\
GE turbine specific & 2 & 1 & 0 & 3 & 0 & 1 & 0 & 0 & 7 \\
Auxiliary oil pump & 1 & 2 & 0 & 1 & 0 & 0 & 1 & 0 & 5 \\
Lube oil components & 2 & 2 & 2 & 0 & 1 & 0 & 1 & 0 & 8 \\
Other & 6 & 4 & 5 & 4 & 3 & 3 & 6 & 1 & 32 \\
Total & 15 & 14 & 14 & 14 & 8 & 5 & 11 & 7 & 88 \\
\hline
\end{tabular}

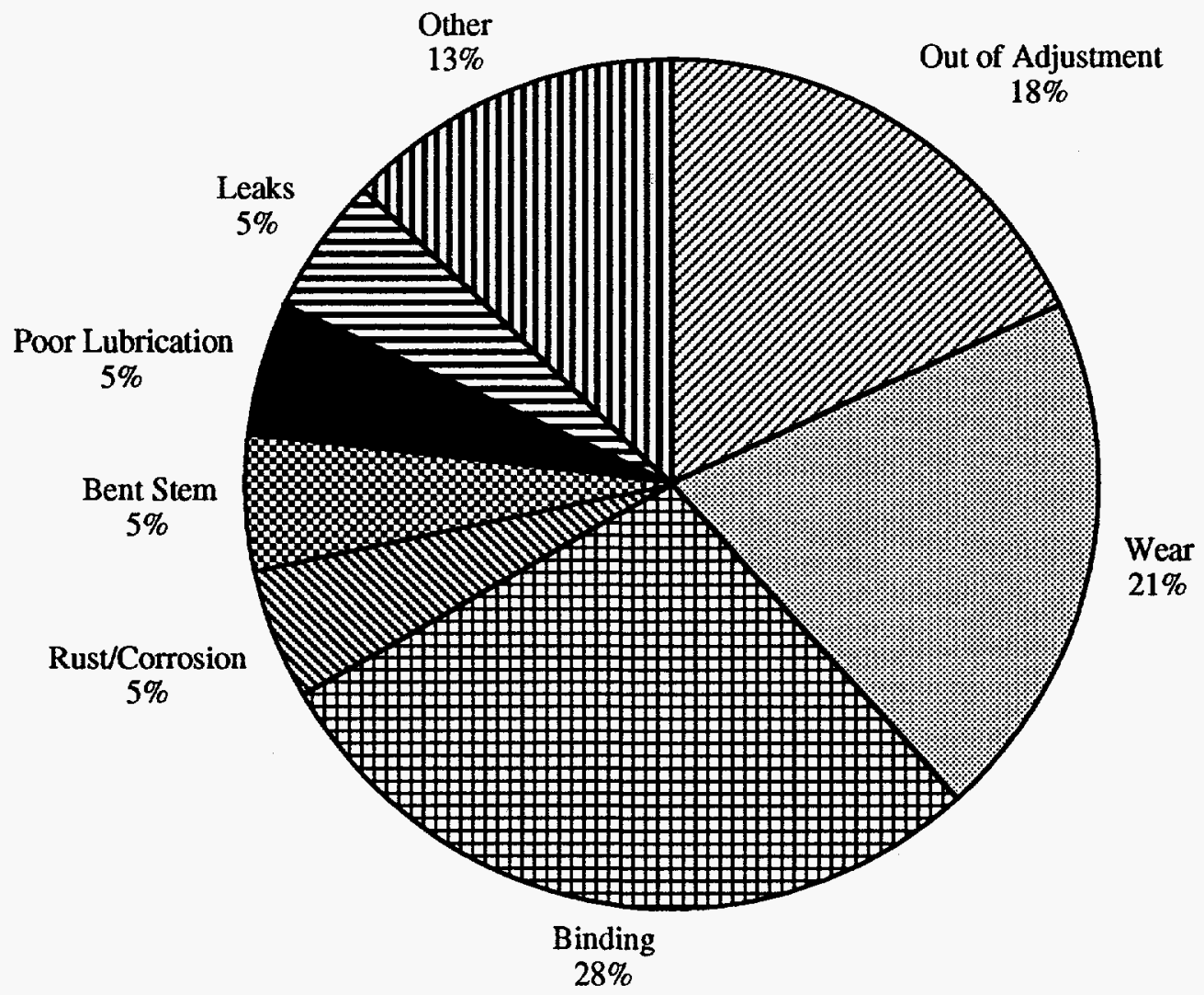

Figure 4.11 Breakdown of governor valve failures

Governor valve malfunctions have manifested themselves in five basic areas, which are often interrelated:

- stem corrosion,

- packing leaks,

- bent valve stems,

- linkage adjustment, and

- wear.
When failures attributed to binding are included with these categories, $\sim 82 \%$ ( 32 of 39 ) of the failures are accounted for. Binding may take the form of stem travel impairment, which may result in erratic behavior or a complete lockup of the valve stem.

Stem corrosion in the governor valve is often evidenced by a buildup of deposits along the portion of the valve stem 
Table 4.4 Breakdown of reported governor valve failures

\begin{tabular}{|c|c|c|c|c|c|c|c|c|c|}
\hline \multirow[b]{2}{*}{ Cause of failure } & \multicolumn{8}{|c|}{ Year } & \multirow[b]{2}{*}{ Total } \\
\hline & 1984 & 1985 & 1986 & 1987 & 1988 & 1989 & 1990 & 1991 & \\
\hline Out of adjustment & 1 & 1 & 2 & 1 & 1 & 1 & 0 & 0 & 7 \\
\hline Wear & 0 & 2 & 2 & 0 & 0 & 0 & 2 & 2 & 8 \\
\hline Binding & 3 & 2 & 2 & 0 & 1 & 0 & 0 & 3 & 11 \\
\hline Rust/corrosion & 0 & 0 & 0 & 1 & 0 & 1 & 0 & 0 & 2 \\
\hline Bent stem & 0 & 1 & 1 & 0 & 0 & 0 & 0 & 0 & 2 \\
\hline Poor lubrication & 0 & 0 & 0 & 0 & 0 & 1 & 0 & 1 & 2 \\
\hline Leaks & 1 & 0 & 1 & 0 & 0 & 0 & 0 & 0 & 2 \\
\hline Other & 0 & 2 & $i$ & 1 & 0 & 1 & 0 & 0 & 5 \\
\hline Total & 5 & 8 & 9 & 3 & 2 & 4 & 2 & 6 & 39 \\
\hline
\end{tabular}

exposed to steam. These deposits are caused by the presence of moisture from operation of the turbine. When stored in a hot wet condition for extended periods of time, corrosion is a distinct possibility. It is the interference of the corrosion deposits with the carbon rings that make up the valve packing that causes binding in the governor valve. In the data examined, binding accounted for $28 \%$ of the governor valve failures.

Corrosion deposits on the valve stem do not automatically cause demand failures. However, cycling of the governor valve during operation can lead to accelerated wear of the carbon rings in the governor valve packing. The wear of the carbon rings can reduce the ability to seal against the valve stem, resulting in packing leaks. Once a leak has developed, the escaping steam can also act to accelerate packing wear.

Review of the operating experience also indicated several failures that can be traced to the governor valve, where degradation of the governor valve could not be identified at the time of inspection. Utility personnel have postulated that thermal expansion of the valve plug has contributed to binding between the plug and the sleeve for certain valves. A design change in 1980 increased the sleeve bore, effectively reducing the possibility of binding due to thermal expansion.

Regardless of the reason, once governor valve plug movement is restricted, it is possible to cause deformation of the stem by buckling. Such restrictions are typically caused by corrosion of the plug and stem. By the time the plug breaks free (from governor servomotor force), permanent deformation of the stem can occur (buckling). The excess packing drag created by a bend could then cause erratic behavior in turbine control, with the potential for OSTs from degraded governor valve response times. However, bent stems accounted for a small percentage of the governor valve failures.

Almost one-fourth (18\%) of the failures attributed to the governor valve are related to the governor valve linkage. These problems normally relate to either adjustment of the linkage or binding due to the accumulation of dirt, caked grease, etc. Periodic adjustment is required to compensate for normal wear in the governor valve/linkage. The problem with dirt/contaminants appears to be caused by excess lubrication. While insufficient lubrication causes binding of the mechanism, excess lubrication tends to collect dirt, debris, and also cake over time. All of this serves to degrade the performance of the governor valve linkage.

\subsubsection{Governor Malfunctions}

Governor malfunctions accounted for a large percentage of the reported failures in the data examined (see Fig. 4.12). However, the number of reports of governor problems is not an accurate measure of governor reliability. One should not expect the governor to perform beyond its design limitations or without adequate maintenance. Listed below are the predominant reasons for apparent governor malfunction:

- dirty oil,

- water-contaminated oil,

- particulate contaminants,

- maladjustment/set point drift, and

- miscellaneous damage.

The narrative for many failures did not specify the failed subcomponent; the only identifier used was "governor." These causes of failure are individually discussed and tabulated below (see Fig. 4.13 and Table 4.5). Note that those 


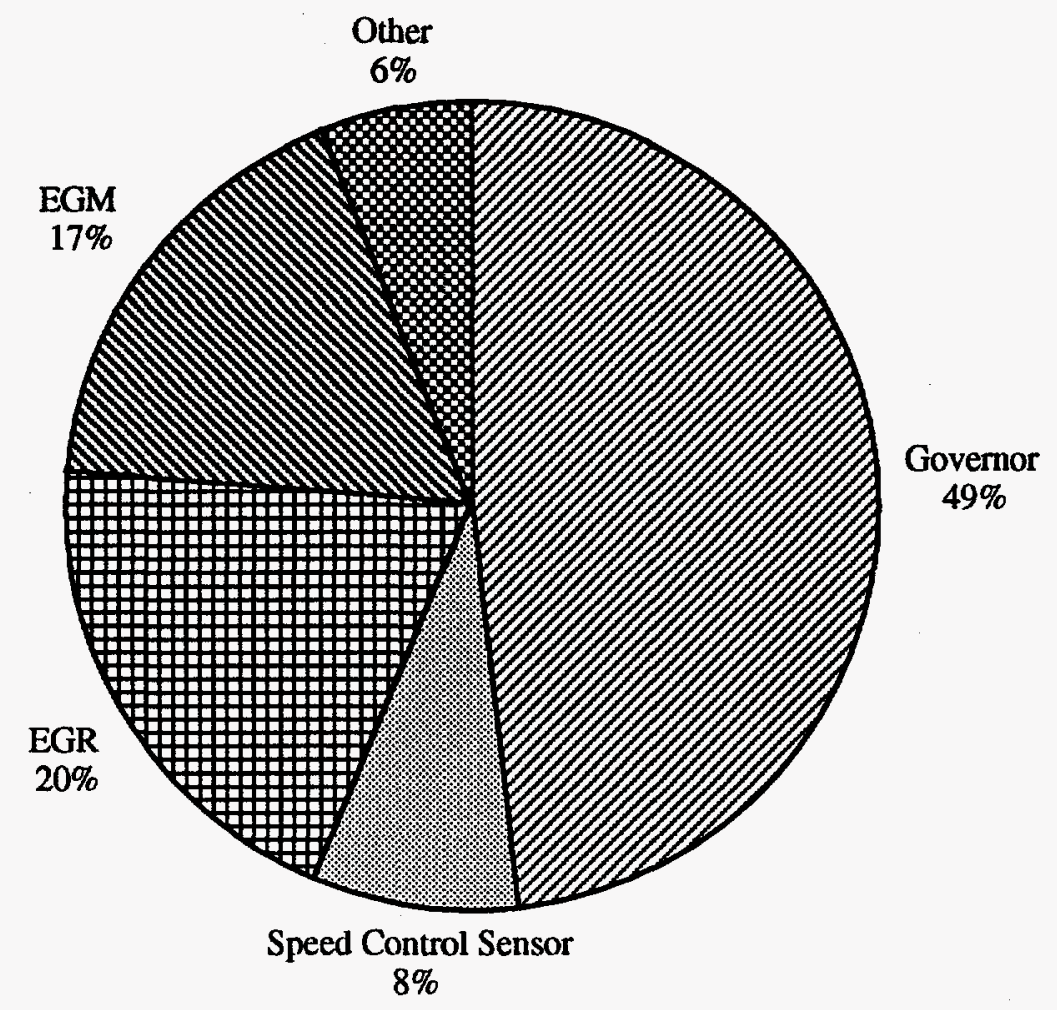

Figure 4.12 Predominant governor subcomponent failures

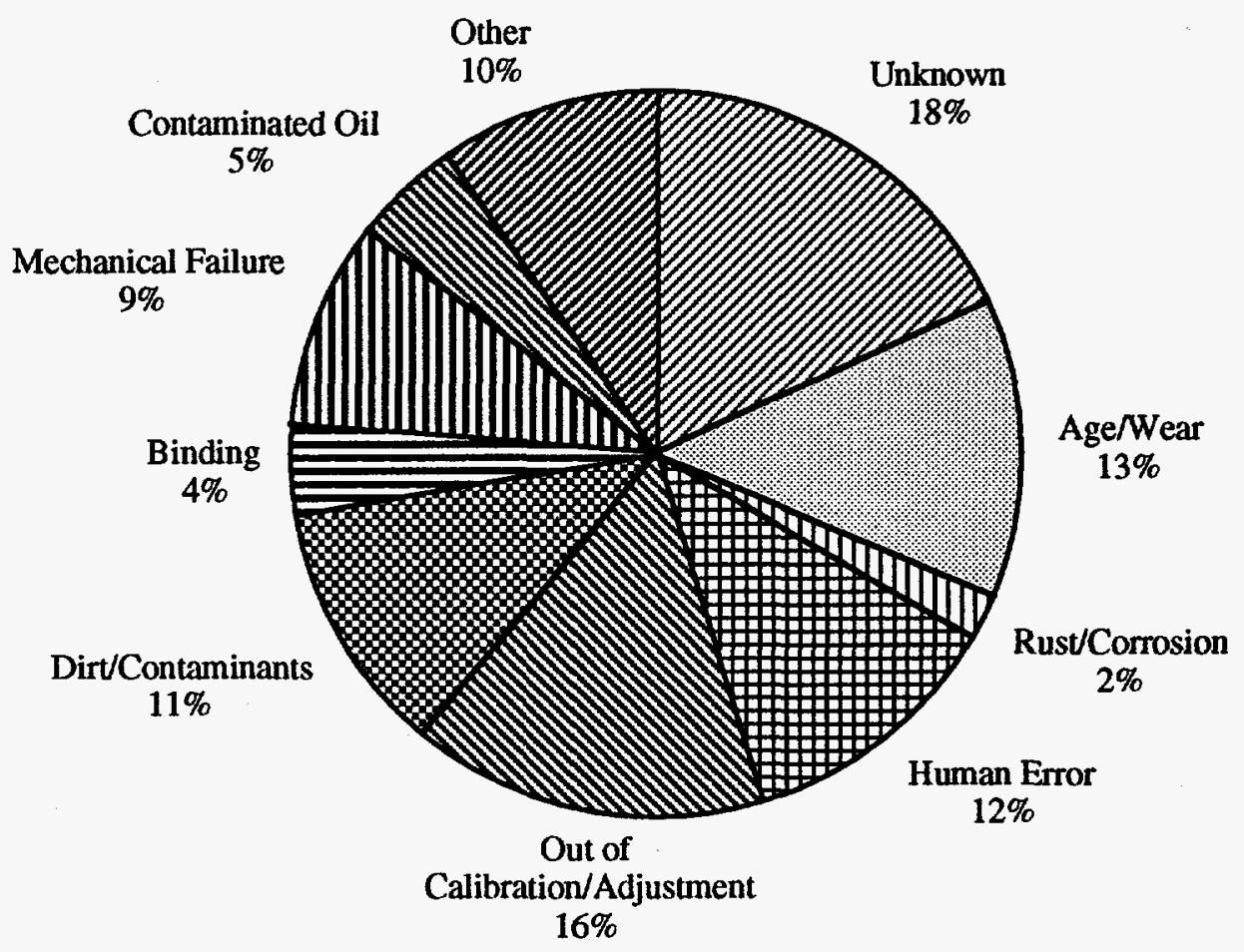

Figure 4.13 Predominant governor failure causes 
Table 4.5 Predominant governor failure causes

\begin{tabular}{lc}
\hline \multicolumn{1}{c}{ Cause } & Number of failures \\
\hline Unknown & 26 \\
Age/wear & 19 \\
Rust/corrosion & 3 \\
Human error & 17 \\
Out of calibration/adjustment & 23 \\
Dirt/contaminants & 16 \\
Binding & 6 \\
Mechanical failure & 13 \\
Contaminated oil & 7 \\
Other & 14 \\
Total & 144 \\
\hline
\end{tabular}

turbines that use EGs draw the governor control oil from the turbine sump. This shared oil system increases the possibility of control oil contamination for these governors due to contamination of the turbine lubricating oil.

\subsubsection{Contaminated Oil}

The quality of the oil used in the governor is critical to its proper function. Supplement 2 to NRC Information Notice 86-14 (Ref. 4) clearly demonstrates performance degradation due to dirty oil. For purposes of this report, dirty oil will be called contaminated oil. Oil contamination can come from several sources: worn bearings, contaminants introduced when the oil was put in the turbine, poor housekeeping during maintenance, leftover machine filings from manufacturing, turbine wear [electronic governor remote/ electronic governor speed control (EGR/EGM) systems], buildup from infrequent changes, and clogged filters.

\subsubsection{Water Contamination}

Water contamination of the governor control oil accounts for $\sim 2 \%$ of the reported governor failures and $5 \%$ of the reported failures for the turbine.

Water contamination has two primary sources: leaking oil coolers and leaking steam seals. Once steam has leaked past the shaft seals, it can condense and contaminate the control oil. For EG systems, the shaft seals most affected are the turbine shaft seals. For PG-type governors, leakage past the governor drive shaft is the most probable path of steam leakage.

Water in the control oil also tends to change the viscosity of the control oil, thus changing the operating characteris- tics of the governor. In addition to changes in the operating characteristics of the governor, water contamination can cause rust on the governor internals by degrading the oil.

\subsubsection{Particulate Contaminants}

Particulate contamination causes loss of governor function by restricting the flow of control oil in the governor. These contaminants enter the governor in several ways. Dirt most easily enters the governor during oil checks or replacement. Once the filler plug is removed, any debris in the vicinity of the filler hole can fall into the governor. Other particulates that can affect governor performance include debris from wear of internal machined parts. Metal filings can accumulate, causing clogging of both orifices and oil passages. Electronic governors must also contend with debris that is introduced to the control oil from the turbine sump. Finally, corrosion products associated with water contamination can result in loose particulate.

\subsubsection{Maladjustment/Set Point Drift}

Problems associated with maladjustment are typically failure to follow procedures. Set point drift, on the other hand, will occur due to natural wear of components, but it is difficult to quantify because it is not reported as a failure unless it leads to turbine inoperability. Drift that is corrected as part of a normal preventive maintenance program will not show up in the data bases. The problem of set point drift, which can easily lead to turbine inoperability, is simple to avoid with periodic calibration of the turbine.

\subsubsection{Miscellaneous Damage}

Miscellaneous damage to the governor is breakage that does not occur as a result of operation. When climbing in the vicinity of the governor and using instrument air lines, sensors, and control oil lines as handholds or steps, various plant personnel, including maintenance workers and operations personnel, can break governor subcomponents. However, such degradation is not a product of governor aging or direct service wear.

\subsubsection{OST Mechanism}

Mechanical OST mechanism failures account for roughly $20 \%$ of the reported failures (Table 4.6). Of the failures attributed to this mechanism, three areas show the greatest potential for degradation: component wear ( $26 \%$ of trip mechanism problems), binding in the mechanism (26\%), and mechanism adjustment (19\%). Dirt accounts for another $4 \%$ of the mechanism problems, with various other nonrecurring failures making up the other $25 \%$. 
Table 4.6 OST mechanism failures

\begin{tabular}{lc}
\hline Cause of failure & $\begin{array}{c}\text { Percentage of } \\
\text { failures for } \\
\text { component }\end{array}$ \\
\hline Age/wear & 26 \\
Adjustment & 19 \\
Dirt/contaminants & 4 \\
Binding & 26 \\
Others & 25 \\
Total & 100 \\
\hline
\end{tabular}

Wear is noticed predominantly in two areas: (1) the trip tappet head and (2) interface between the head lever and the tappet nut (see Figs. 3.9 and 3.12). The trip tappet head has gone through several design modifications that have changed the shape of the head and also the material. The data reviewed show only two broken trip tappet heads since the change from the ball type to the molded head in 1985 . The failures in the old style head occurred because the ball type head was known to chip and crack from the impact of the trip pin. There is no history of this problem recurring after the molded trip tappet was installed.

Wear between the head lever and the tappet nut can cause inadvertent turbine trips (see Fig. 3.9). Wear in this area cannot be corrected by adjustment. Once the seating surface has been damaged, one or both pieces will have to be replaced. Wear of these two surfaces is inevitable due to friction. The actual mechanism is a rounding of the edges, which reduces the 0.030 - to 0.060 -in. engagement required to prevent spurious trips from vibration. Lubrication to reduce friction and the subsequent wear has been shown to increase inadvertent trips. This was reported by a particular utility that eliminated spurious turbine tripping by removing an oily film that accidentally accumulated on the tappet nut and the head lever. This experience provides an insight into the sensitivity of the turbine OST mechanism.

\subsubsection{T/T Valve}

Very few failures were reported for the $T / T$ valve; $T / T$ valve failures accounted for $<3 \%$ of the failures reported. The failure data show no pattern of any sort that would indicate anything other than normal wear for both the valve and mechanism. Of the failures examined, no two were the same. The one area with a potential for degradation is the mating surface between the trip hook and latch-up lever. The trip hook is actuated by the OST mechanism or the trip solenoid in the event of a manual trip. While this area appears to have the potential for wear-related problems, the failure data do not indicate significant historical degradation. 



\section{Testing}

\subsection{Background}

The purpose of periodic testing is to provide a quantifiable method of ensuring that the turbine will perform the intended function when an automatic start signal is received. Test results should confirm that the turbine will both start in a controlled manner and maintain the reference speed without evidence of erratic behavior. Testing should simulate the environment and system conditions for a demand start as closely as possible, including temperature and pressure transients, time constraints, and system status (cold start vs hot start).

Current test requirements were identified, and historical failures were examined to determine which components were failing. This was followed by analysis of the failures to determine whether the degradation could be identified by testing and whether current test methodologies identify component degradation prior to turbine system failure.

Of primary interest is verification that the speed control system is functioning properly. This includes the governor, governor valve, servomotor, and associated linkages. Periodic testing should demonstrate that the OST mechanism is capable of halting turbine operation if the turbine is not capable of maintaining a stable speed, thereby preventing damage to the turbine, pump, and associated piping.

\subsection{Current Requirements}

In general, current technical specification test requirements are structured around the pump driven by the turbine, rather than around the turbine itself. As a result, technical specification performance criteria are primarily related to developed head and flow, rather than measures of turbine performance.

Once per month (typically) the AFW system is required, by technical specifications, to be started. The system must demonstrate that the pump can deliver a specified flow at a specified pressure. The flow/pressure combination is not required to be at design conditions and is typically conducted with the pump operating under miniflow conditions. Full-flow testing at design pressures is not required and is not commonly performed. Rather, the pump is normally run at minimum-flow conditions. Typically, the turbine is started for monthly testing by opening the SAV (using its power operator) instead of using a slow, controlled turbine start to initiate pump testing. Testing of the automatic start signals for the turbine is done once per 18 months (typically). This testing requires verification that the turbine will start automatically upon receipt of signals such as loss of off-site power (low bus voltage) or low levels in more than one steam generator. Note that the turbine is not necessarily started in conjunction with the start signal tests; rather the SAV or T/T valve will open in response to this signal. Testing may be done under depressurized conditions.

Unlike the AFW system, the BWR RCIC and HPCI technical specifications require low steam supply pressure testing and full-flow testing. While technical specifications do not specifically require testing of the turbine, they do require testing the turbine/pump combination at both normal and low steam pressure conditions. The normal requirements are as follows:

Quarterly: Verify that the RCIC and HPCI pumps develop design flow (typically 500 to $600 \mathrm{gal} / \mathrm{min}$ for RCIC and 5000 to $6000 \mathrm{gal} / \mathrm{min}$ for HPCI) through the test flow path at normal steam pressures ( $-1000 \mathrm{psig})$.

Every 18 months: Verify that the pumps are able to develop the same flow rates when the turbines are driven with 150 to 200-psig steam.

Testing at the extremes of steam supply pressures and at full-flow conditions provides a better indication that the turbine will operate over the entire range of design conditions, as well as a better indication that it will perform as required if called upon under a demand situation.

The results from cold and prewarmed turbine tests have indicated significant differences in startup time, startup transient characteristics, exhaust line and valve stability, and, for HPCI turbines, stop valve opening transients caused by changes in balance chamber pressure.

The magnitude of these unique differences in plants primarily is a function of the length of piping between the turbine assembly and the upstream SAV. This factor should be considered when determining the individual test methodologies for the turbine system. 


\subsection{Failure Detection}

In examining historical failure data, the failures of most concern are the failures discovered in demand situations. Failures presently being discovered by programmatic means such as surveillance testing, inspection, walkdowns, etc., are being identified by appropriate means. Demand failures are of greater consequence to plant operation and therefore demand closer examination. The four components with the largest number of demand failures are the governor, the turbine, the mechanical OST mechanism, and the governor valve.

It can be seen from previous data that a major cause of governor failure is dirty or contaminated oil. Likewise, of the failures noted as being related to the turbine proper, contaminated lubricant was a major factor. For the turbine proper, poor lubricant significantly affects bearing life. In both cases such degradation could be mitigated by periodic oil sampling with resulting corrective action when degradation is detected.

A major cause of OST failures is wear of the mechanism. Close inspection of these components periodically will allow detection of this wear.

The governor valve is subject to stressors that may not be detected without turbine operation. The area of the governor valve that is most susceptible to degradation is the valve stem. The section of valve stem exposed to steam varies with the steam supply pressure and the required flow rate from the pump. As the steam pressure decreases, the governor valve must open further, admitting a larger volume of steam, and thus achieving constant pump output. At high supply steam pressures, the governor valve operates very close to the valve seat. Under this condition stem travel is minimal. This means that stem degradation may have occurred, but will not be discovered until the valve is required to open further but cannot. Periodic sampling and inspection will provide for the detection of oil and wear problems. The governor valve has to function during surveillance testing, but if the turbine is not operated across the full range of steam pressures, there is no verification that the governor valve has freedom of motion for the full range of travel.

\subsection{Test Methodology Deficiencies}

An apparent deficiency with these requirements is that turbine operability for the full range of design operating conditions is not demonstrated. As discussed in Chap. 2, the function of the AFW system is to supply water that is turned into steam, thus removing decay heat from the reactor. The goal is to reduce the reactor temperature below $350^{\circ} \mathrm{F}$, at which time the residual heat removal (RHR) system initiates. Because the turbine steam supply comes from the steam generators, a reduction in the steam generator temperature (based on reduced reactor temperature) will consequently reduce the pressure of the steam supplied to the turbine. Note that saturation pressure for $350^{\circ} \mathrm{F}$ is about $120 \mathrm{psig}$. A reduction in the steam supply pressure will reduce the amount of steam admitted to the turbine for a given governor valve position. Therefore, the governor valve must open further to maintain the turbine "on speed." If the turbine is not tested at these lower supply pressures, there is no verification that the speed control system will maintain turbine control and stability at the point of operation before RHR actuation. For example, deformities in the governor valve stem near the end of travel limits (corrosion or bent stem) may not affect speed control until the point of deformity becomes the point about which the governor is trying to control turbine speed.

Also note that the ability of the turbine/pump combination to operate properly at full-load conditions (high feed flow) is not required for AFW systems. High flow from the pump requires greater steam flow than is required for minimumflow conditions. Absence of high-flow testing, as in the case of absence of low steam pressure testing, results in demonstration of turbine performance under a very limited set of conditions that are not representative of design basis conditions.

\subsection{Vendor Recommendations}

Terry and Woodward testing recommendations were reviewed relative to existing regulatory requirements. It should be noted that many utilities have adopted at least a part of these vendor recommendations. However, because they are not requirements, it is difficult to ascertain the extent to which they are followed.

The vendor recommendations are discussed in the following paragraphs. Portions of the following text have been excerpted from GE Service Information Letter 336 by permission. ${ }^{5}$ Recommendations should be evaluated for applicability to the specific nuclear facility (e.g., full-flow testing is not possible at all plants).

Speed Control-Testing of the speed control should verify that the SAV (if normally closed) opens in the required stroke time. It should open without exceeding the maximum allowable stroke time. SAV stroke time should not 
fall below the minimum value that prevents unacceptable turbine acceleration and OSTs. The governor valve linkage should also be checked for freedom of movement, and the governor valve stem should be checked for evidence of corrosion. If the T/T valve is used to start the turbine, verify during a turbine start that the balance chamber pressure is adjusted properly. Verify during turbine start that oil pressure is adequate to control governor, ramps are smooth, overshoot is minimum, and steady state operation can be achieved and maintained.

OST mechanism-Before starting, verify that trip tappet is not binding, the head lever pivots freely, the tappet nut seats properly, the trip spring is adjusted to give 28 to $32 \mathrm{lb}$ of force in the direction of connecting rod movement, and impact space is adequate between the connecting rod and the trip hook to accommodate a trip.

An operability demonstration of the turbine should include not only steady state pump flow and pressure data, but also quick-start control capability and proper valve sequencing. Testing should simulate closely the actual startup sequence of the system following an auto-initiation signal. 1

Occasionally, system valves are opened in sequences different from those that occur during an automatic startup sequence. Opening the HPCI turbine stop valve before opening the upstream steam supply valve is a major concern. To demonstrate that a stop valve operates properly, it must be opened against steam forces. Furthermore, opening the stop valve before opening the upstream steam supply valve results in the turbine control system demanding maximum speed before admitting steam to the turbine because the acceleration control system is bypassed. It is highly probable that an improper valve opening sequence could cause system failure either from high steam flow isolation or from a turbine OST. 


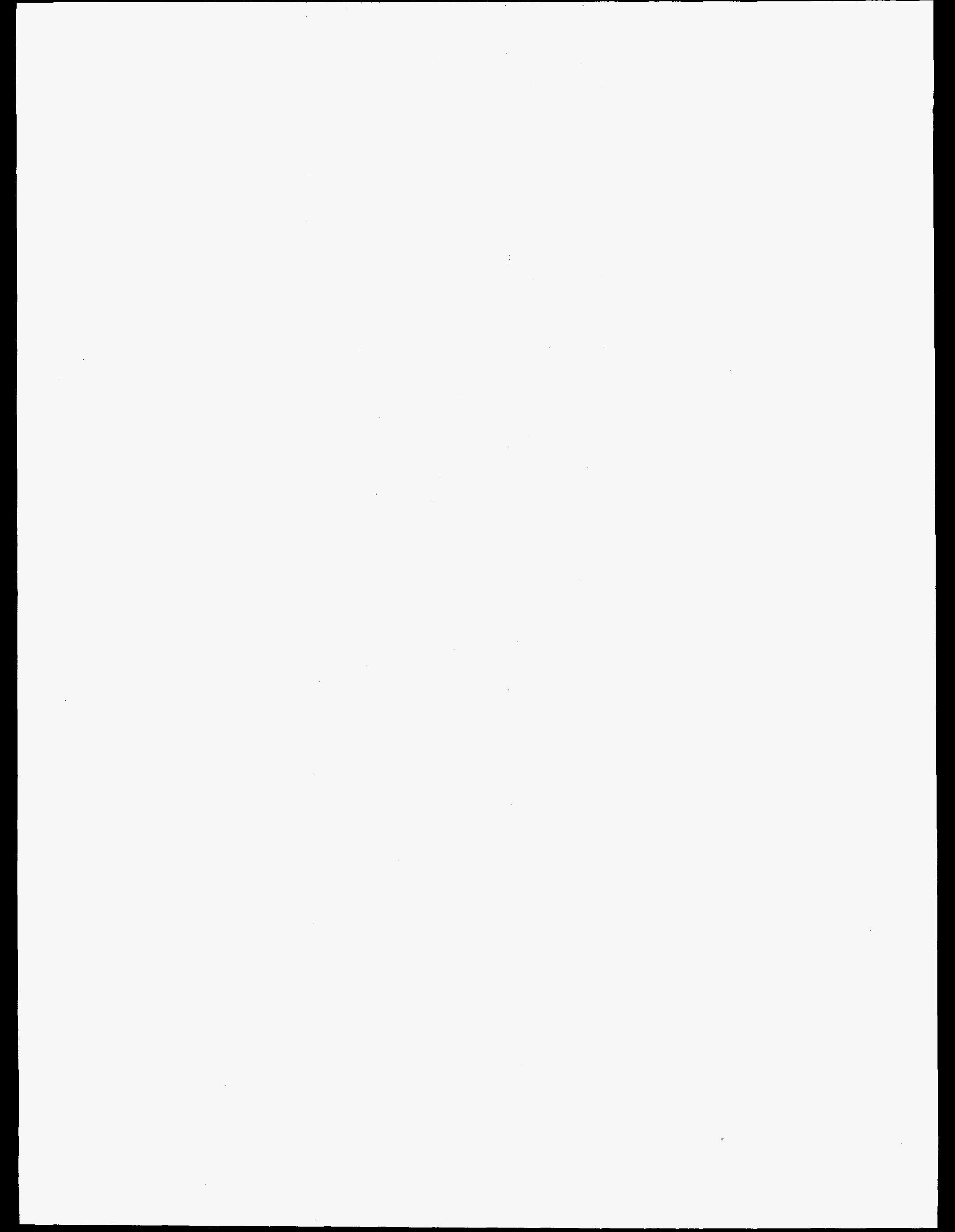




\section{Summary and Conclusions}

The aging study of turbine pump drives has shown that this component has the capability of functioning in a reliable manner. The data evaluated (i.e., between 1984-1991) indicate, in general, a trend for decreases in the number of failures detected during demand conditions from 1984 to 1991. However, $20 \%$ of the failures noted in 1991 were discovered under demand circumstances. Also as a percentage of the total failures per year, there was a $21 \%$ increase in the number of failures detected by programmatic methods between 1984 (48\%) and 1991 (69\%). This trend is positive since it is preferred to detect failures programatically rather than in demand situations. These methods include routine testing, walkdowns, and scheduled preventive maintenance. Experience and education appear to have a major part in these changes. With proper maintenance the turbine can be a reliable part of nuclear plant safety systems.

Examination of the data indicates that the governor is involved in a significant portion of turbine failures. Note that the electronic analog governors (EG series), currently in use at many nuclear power plants, may not be available several years from now. According to Woodward, when it is no longer economically practical to continue the manufacture of this type of governor for nuclear power use, it will be replaced with the newer series of digital governors. If a new source for replacement governors cannot be identified, utilities will be forced to change speed control sys- tems. Again, this situation has not occurred yet, but it is probable. It may be wise on the part of utilities, either in part or as a whole, to investigate potential problems with interfaces, environmental qualification testing, parts inventory, and training.

Three areas are particularly important to enhancing turbine system reliability:

- Consideration should be given to periodically performing a complete analysis of turbine and governor oil to reveal the presence of contaminants and/or oil degradation. The experience of each utility should be used to determine a time period that will increase reliability (e.g., annual or semiannual analysis).

- Consideration should be given to calibrating governors on a regular basis (e.g., once per refueling cycle). Currently, this is not a requirement in the plant technical operating specifications.

- Consideration should be given to periodically verifying OST operation. One method of verification would be to manually take the turbine to overspeed and verify the function of the mechanical OST mechanism. This will give a positive indication that the entire mechanical OST mechanism is properly functioning. 



\section{References}

1. Electric Power Research Institute, EPRI Nuclear Maintenance Application Center, Terry Turbine Controls Guide, NP-6909, 1990.

2. D. A. Casada, Martin Marietta Energy Systems, Inc., Oak Ridge National Laboratory, "Auxiliary Feedwater Aging Study," USNRC Report NUREG/ CR-5404 (ORNL-6566/V1), March 1990.*

3. C. Hsu, "Operational Experience Involving Turbine Overspeed Trips," USNRC Report AEOD/C602, August 1986.
4. U.S. Nuclear Regulatory Commission, "Overspeed Trips of AFW, HPCI, and RCIC Turbines," Information Notice 86-14, Supplement 2, August 26, 1991.

5. General Electric Nuclear Services, Service Information Letter 336 Rev. 1, "Surveillance Testing Recommendations for HPCI and RCIC Systems," December 8 , 1989.

\footnotetext{
* Available for purchase from the National Technical Information Service, Springfield, VA 22161.
} 


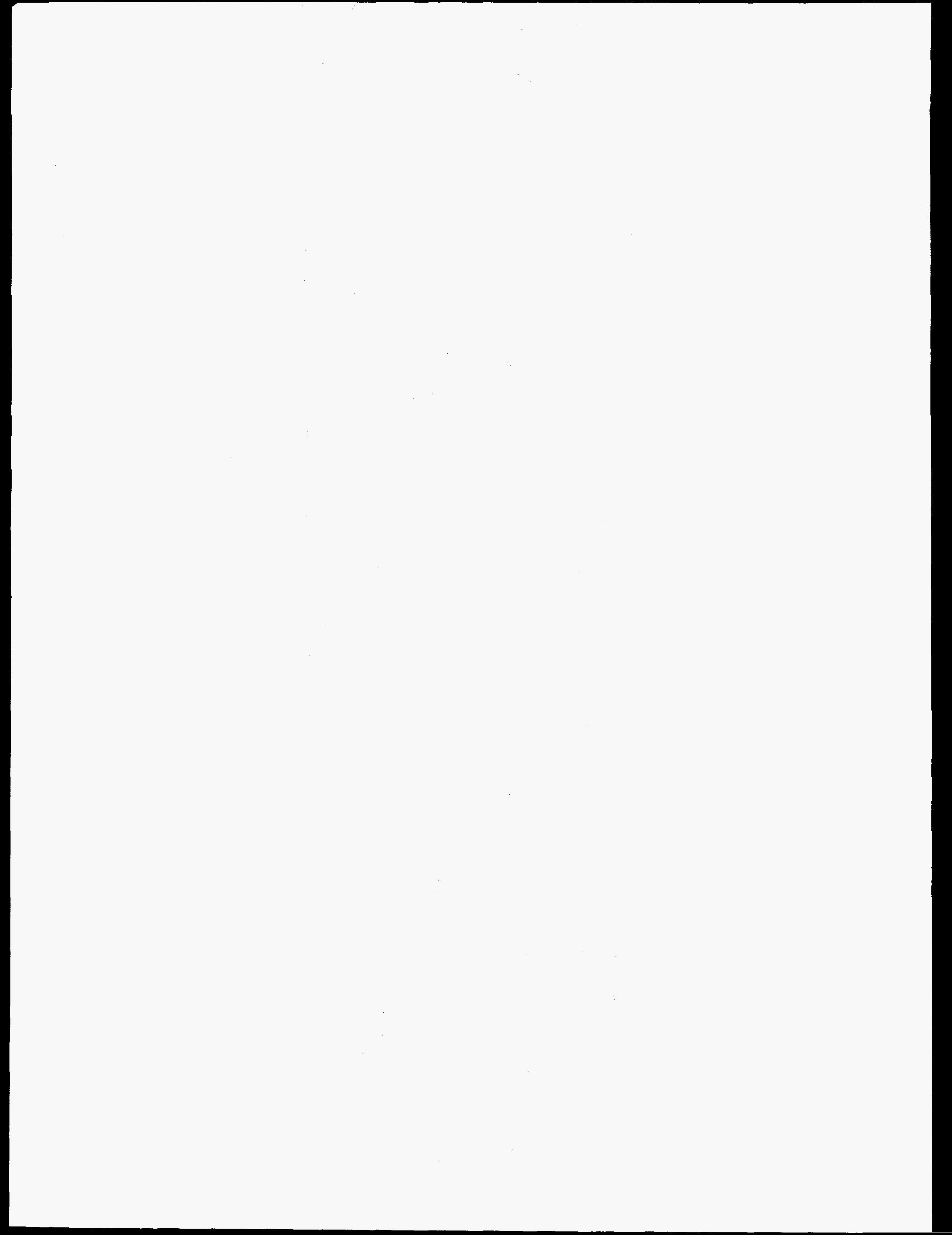


Appendix A

Governor Configurations 



\section{Appendix A \\ Governor Configurations}

\section{A.1 PG Series}

The pressure-compensating (PG) series of governors is identical in basic configuration (see Fig. A.1). They are all mechanical/hydraulic governors with a centrifugal flyweight assembly, a self-contained oil sump, and a geardriven oil pump. While there are many moving parts in the governor, very few adjustments must be made. Adjustments are normally limited to the compensating needle valve and the linkage between the governor valve and the governor. This linkage will be covered with the governor valve.

The basic governor consists of an oil pump, accumulators, speeder spring, flyweight assembly, thrust bearing, pilot valve plunger, rotating bushing, buffer compensation system, and a power cylinder (servomotor). The governor drive shaft passes through the governor base engaging the rotating bushing. The pump supplies pressurized oil for operation of the basic governor section, the speed setting section, and all other auxiliary features. The accumulators provide a reservoir of pressurized oil and function as relief valves, sending excess oil to the governor sump. The upper end of the rotating bushing holds the flyweight assembly, which is geared directly to the turbine.

Flyweight centrifugal force and speeder spring force oppose each other to balance the pilot valve plunger. A disturbance of this balance moves the pilot valve plunger up or down: flyweight centrifugal force tries to lift the plunger, and speeder spring force tries to lower the plunger. When the turbine is on speed these forces are equal. In this position, the control land on the pilot valve plunger is centered over the regulating port in the rotating bushing. No oil, other than leakage make-up, flows to or from the buffer compensation system or servomotor. A change in either of

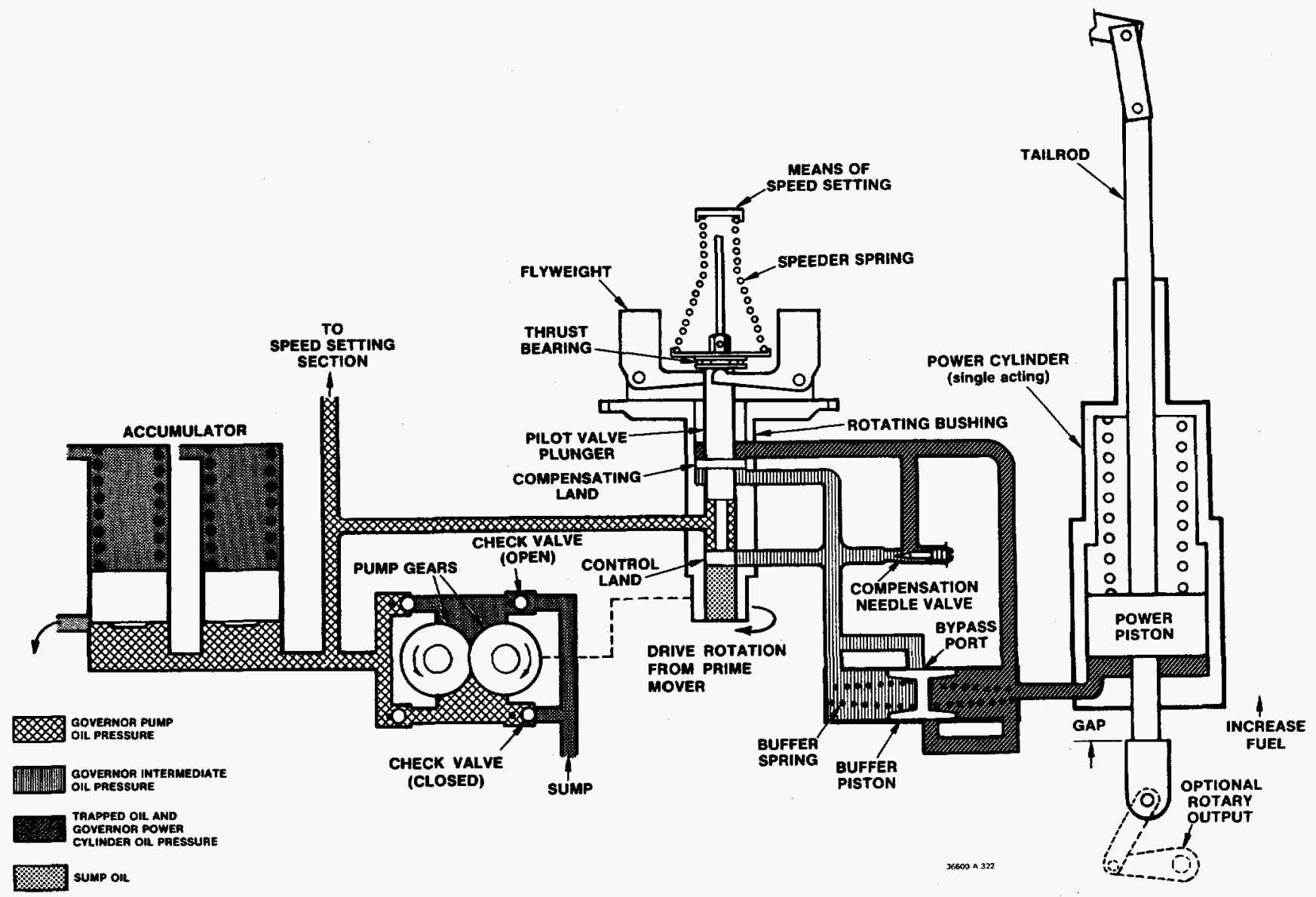

Figure A.1 Mechanical governor schematic. Reprinted with permission from Woodward Governor Company, "PGG Governor Manual 36627B," 1979 
these two forces will move the plunger from its centered position. The plunger will be lowered when (1) additional load is on the turbine or (2) the governor speed setting is raised. The pilot valve plunger will be raised when (1) the load on the turbine is decreased or (2) the governor speed setting is lowered.

When the plunger is lowered (an underspeed condition), pressurized oil is directed into the buffer compensation system and servomotor to raise the power piston and increase steam. When the plunger is lifted (an overspeed condition), oil is permitted to drain from these areas to sump, and the power piston moves downward to decrease steam.

The buffer compensation system, which stabilizes turbine speed after a change in load or speed setting, is made up of the following components:

1. the buffer piston and springs,

2. the compensation needle valve,

3. the compensation land on the pilot valve plunger, and

4. the hydraulic circuits between the pilot valve plunger and the servomotor.

A demand increase (increasing the required speed or load) on the turbine causes flyweights to move inward. This is caused by increase in speeder spring force from a speed adjustment or a reduction in the centrifugal force from the load increase and subsequent speed decrease.

Increasing the speed setting or load on the turbine at a given speed setting has identical effects. In either case, the flyweights move inward (underspeed) due to either the increase in speeder spring force or to the decrease in centrifugal force caused by the decrease in turbine speed as load is added. The movement of the flyweights is translated into a downward movement of the pilot valve plunger. This directs pressure oil into the buffer system, causing the buffer piston to move toward the servomotor. The oil displaced by the movement of the buffer piston forces the power piston to move upward in the direction of increase. The oil pressures on either side of the buffer piston are simultaneously transmitted to opposite sides of the compensation land, the higher pressure on the lower side.

This pressure differential is proportional to buffer piston displacement, buffer spring rate, and needle valve setting. The upward force produced is added to flyweight force to help restore the balance of forces and recenter the pilot valve plunger. This enables the governor to stop the increased steam flow necessary for turbine acceleration at a point that will produce steady state operation at the increased demand.

As the turbine continues to accelerate toward the set speed, the compensation force is gradually dissipated to offset the continuing increase in flyweight force. This is done by equalizing the pressures on each side of the compensation land through the needle valve at a rate proportional to the continued rate of acceleration. This minimizes speed overshoot and permits the governor to quickly reestablish stable operation. The needle valve setting determines the rate at which the differential pressure is dissipated and allows the governor to be "matched" to the characteristics of the turbine and its load. The compressed buffer spring returns the buffer piston to its centered position as the pressure differential is dissipated.

The compensating needle valve determines the rate at which oil is admitted to or removed from the servomotor. If the compensating needle valve is open too far, oil is exchanged between the governor and the servomotor so rapidly that the system does not have a chance to stabilize (hunting). In essence, the system overreacts. When the valve is closed too far the system response is slow, potentially allowing the system to go to overspeed before the governor can regain control of the turbine. Therefore, the adjustment of the compensation needle valve directly affects the stability of the turbine during load changes.

Whenever large changes in speed setting or load are made, the buffer piston will move far enough to uncover a bypass port in the buffer cylinder. This restricts the pressure differential across the buffer piston to some maximum value and also permits oil to flow directly to the servomotor. Thus, the power piston is made to respond quickly to large changes in speed setting or load.

Decreasing the speed setting or load on the turbine at a given speed setting is also identical in effect and causes a reverse action to that described previously. The flyweights move outward (overspeed), lifting the pilot valve plunger and allowing oil to drain from the buffer compensation system. The buffer piston moves away from the servomotor, permitting oil to drain from the area under the power piston, which then moves downward in the direction of decrease. The differential pressures acting across the compensation land produce a net downward force that tends to assist the speeder spring in recentering the pilot valve plunger slightly before the turbine has fully decelerated. This stops power piston movement when it has reached a point corresponding to that amount of steam required for 
steady state operation at the new lower speed or load. Dissipation of the compensation force occurs in the same manner as previously described and, in this instance, minimizes speed undershoot.

\section{A.2 EG Series}

The electronic governor (EG) used with the turbines is typically a Woodward model EG. The EGs used for all three systems are very similar in configuration. According to the vendor the difference between the governors used for advanced feedwater (AFW)/reactor core isolation cooling (RCIC) systems and high-pressure coolant injection (HPCI) systems is limited to several capacitors. The EG configuration and operational description for all three systems are discussed in the following paragraphs.

The EG is equipped with an adjustable ramp generator, which controls turbine acceleration up to the point at which the device measuring pump output (usually flow) indicates that the pump is producing an acceptable volume of cooling water.

In addition, a local speed control is incorporated in the turbine governor system in the form of an overspeed trip (OST) controller.
The governor is comprised of several components that combine to form the governor system:

1. the resistor box,

2. magnetic pickup,

3. ramp generator/signal converter,

4. overspeed test controller speed-setting potentiometer,

5. EGM control box,

6. EGR electro-mechanical-hydraulic actuator, and

7. remote servomotor.

The power supplied to operate the governor passes through the resistor box (dropping resistor), where it is reduced to $48 \mathrm{~V} \mathrm{dc}$.

The speed signal for the EGM control box comes from the electrical impulses generated by a magnetic pickup positioned near a rotating gear, which is attached to the turbine shaft. As each tooth moves past the pickup, a voltage pulse is produced in the pickup coil. In the EGM these ac voltage pulses pass through a frequency-to-voltage converter that converts them into a dc voltage proportional to speed. This dc voltage is then fed into the summing junction where it is compared to the reference speed voltage signal (see Fig. A.2).

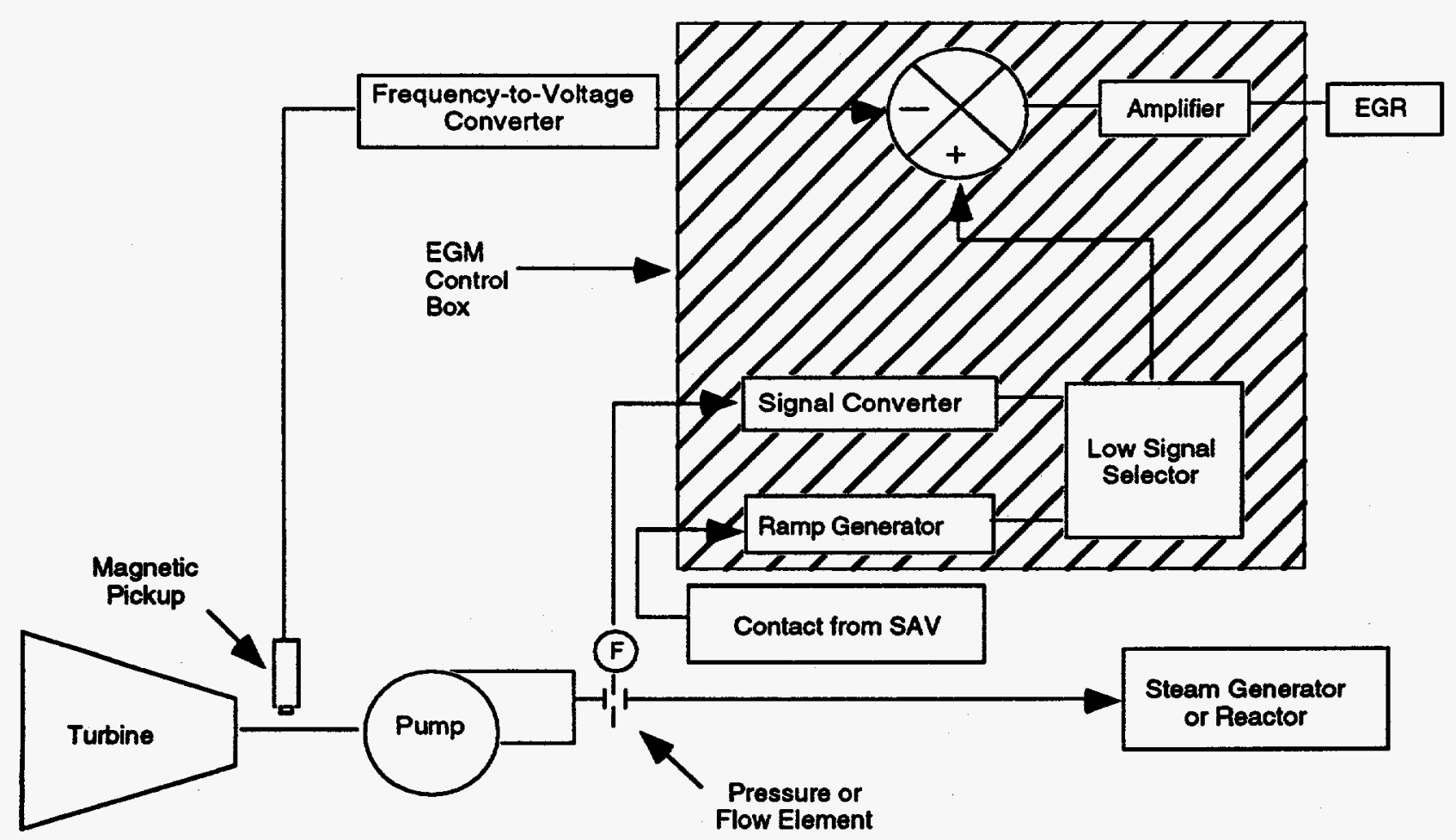

Figure A.2 EG stability adjustment 
A speed-setting potentiometer establishes the reference voltage at the input to the amplifier, which corresponds to the speed at which the turbine is required to drive the pump.

The two voltages (from the magnetic pickup and the speedsetting potentiometer) are of opposite polarity. When they are equal in magnitude, the net result is that the voltage input to the amplifier will be zero. Therefore, since the actuator calls for governor valve movement based on the difference between the two signals, the turbine will operate at steady state. When there is a difference between these two voltages, the EGR actuator is called upon to modify the position of the governor valve to maintain the turbine speed.

The amplifier section has two controls: gain and stability. The amplifier inputs are the dc voltage proportional to speed and the reference voltage. Governor stability is maintained by proper adjustment of the amplifier gain and the delay in a feedback circuit around the amplifier. This feedback circuit uses the amplifier output as an input signal. The amplifier is equivalent to the pilot valve porting found in the PG governors, and the stability adjustment is analogous to needle valve adjustment.

If the turbine load changes, there is a change in turbine speed and also the frequency of the electrical impulses transmitted by the magnetic pickup. This change in impulse frequency causes a change in the output voltage of the speed section of the control box, so that this voltage differs from the speed reference voltage. This voltage difference is fed into the amplifier. The amplifier then supplies an output voltage to the hydraulic actuator, which moves the governor valve to increase or decrease the steam to return the turbine speed to normal. When the hydraulic actuator is used with a remote servomotor, the pilot valve plunger within the actuator directs oil to or from the remote servo- motor that, in turn, moves the governor valve to increase or decrease the steam to return the turbine speed to normal. As the turbine speed returns to normal, the speed input signal changes so that the output voltage of the speed section is again equal to the output voltage of the speed reference section. This stops further action, and the turbine continues to operate at the new steam setting until there is another load change.

Changes in the reference speed are accomplished by adjusting the speed-setting potentiometer. Motor operation of the speed-setting potentiometer is possible to allow for remote speed changes.

The EGR actuator (see Fig. A.3) adjusts the turbine steam supply in accordance with the output signal of the EGM. The heart of the EGR actuator is an electro-hydraulic transducer that directs oil to and from the servomotor, which actuates the governor valve linkage. The transducer consists of a solenoid, which is attached to the pilot valve plunger. The pilot valve plunger controls oil flow to and from the servomotor. The solenoid directs pilot valve plunger movement in accordance with EGM output. Through the governor valve linkage the servomotor positions the governor valve.

Each actuator has its own oil pump to develop the hydraulic pressure needed to move the servomotor. Most of the actuators use oil from the turbine lube oil system; however, other external oil sources may be used. It is important to note that oil pressure is not developed from the oil pump until the turbine starts to roll.

The remote servomotor designed for use with the EGR actuator is a differential servomotor in a separate housing. Tubing connects the hydraulic circuits of the actuator to those in the remote servomotor.

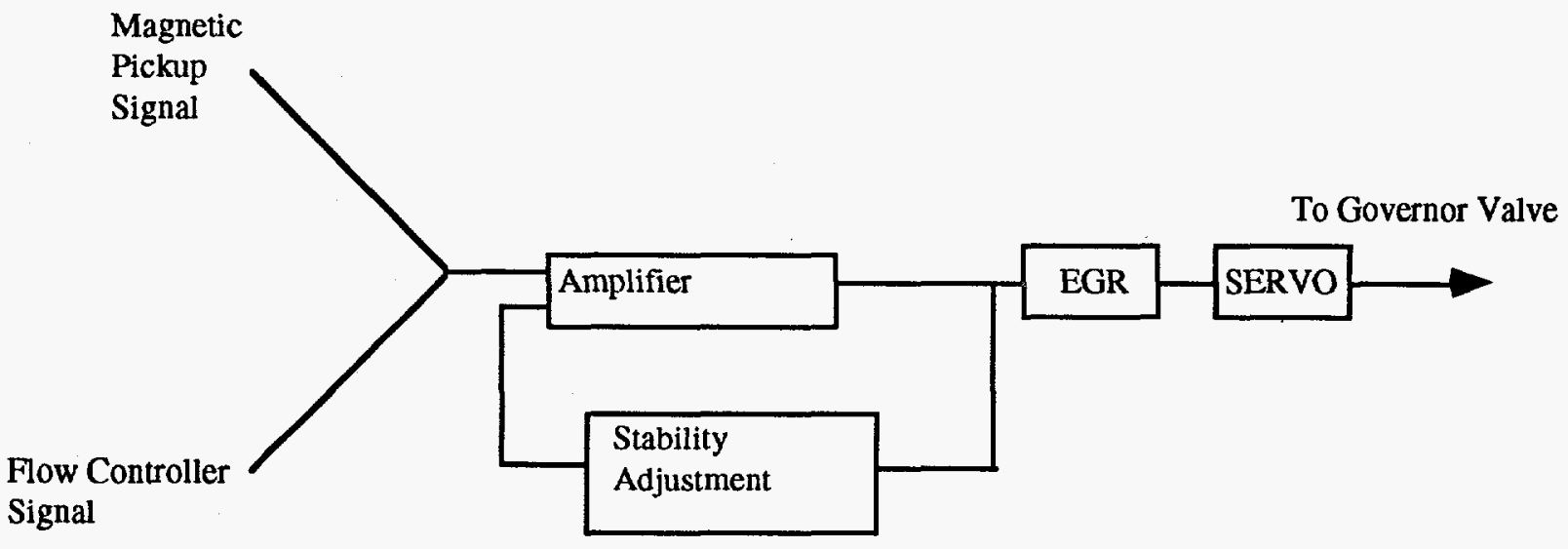

Figure A.3 EG stability adjustment 
EGR actuators provide hydraulic-mechanical steam setting control in response to appropriate electric control signals. The actuators may be adjusted to move toward either minimum or maximum steam in the absence of an electric control signal. 

NUREG/CR-5857

ORNL-6713

Dist. Category RV

\section{Internal Distribution}

1. C. W. Ayers

2. D. A. Casada

3. R. D. Cheverton

4-24. D. F. Cox

25. E. C. Fox

26. R. G. Gilliland

27. H. D. Haynes

28. J. D. Kueck

29. K. H. Luk

30. K. L. McElhaney
31. A. B. Poole

32. C. E. Pugh

33. C. C. Southmayd

34. R. H. Staunton

35. ORNL Patent Office

36. Document Reference Section

37. Central Research Library

38-40. Laboratory Records Department

41. Laboratory Records (RC)

\section{External Distribution}

42. G. Sliter, Electric Power Institute, P.O. Box 10412, Palo Alto, CA 94303

43. J. W. Tills, Institute for Nuclear Power Operations, 1100 Circle 75 Parkway, Atlanta, GA 30339-3064

44. R. J. Lofaro, Brookhaven National Laboratory, Bldg. 130, Upton, NY 11973

45. R. P. Allen, Battelle-PNL, MS P8-10, P.O. Box 999, Richland, WA 99532

46. J. P. Vora, U.S. Nuclear Regulatory Commission, Office of Research, Division of Engineering Technology, Electrical, Materials, and Mechanical Engineering Branch, MS T-10 E10, Washington, DC 20555

47. G. H. Weidenhamer, U.S. Nuclear Regulatory Commission, Office of Research, Division of Engineering Technology, Electrical, Materials, and Mechanical Engineering Branch, MS T-10 E10, Washington, DC 20555

48. M. E. Mayfield, U.S. Nuclear Regulatory Commission, Office of Research, Division of Engineering Technology, Electrical, Materials, and Mechanical Engineering Branch, MS T-10 E10, Washington, DC 20555

49. O. P. Gormley, U.S. Nuclear Regulatory Commission, Office of Research, Division of Engineering Technology, Electrical, Materials, and Mechanical Engineering Branch, MS T-10 E10, Washington, DC 20555

50. J. E. Jackson, U.S. Nuclear Regulatory Commission, Office of Research, Division of Engineering Technology, Engineering Issues Branch, MS T-10 C9, Washington, DC 20555

51. P. L. Campbell, U.S. Nuclear Regulatory Commission, Office of Nuclear Reactor Regulation, Electrical and Mechanical Engineering Branch, OWFN, 7E23, Rockville, MD 20852-2738

52. C. F. Nelson, Sandia National Laboratory, P.O. Box 5800, MS 0737, Albuquerque, NM 87185

53. H. L. Magleby, Idaho Engineering Laboratory, MS 2406, P.O. Box 1625, Idaho Falls, ID 83415

54. Office of Assistant Manager for Energy Research and Development, Department of Energy, Oak Ridge Operations, Oak Ridge, TN 37831

55-56. Office of Scientific and Technical Information, P.O. Box 62, Oak Ridge, TN 37831 


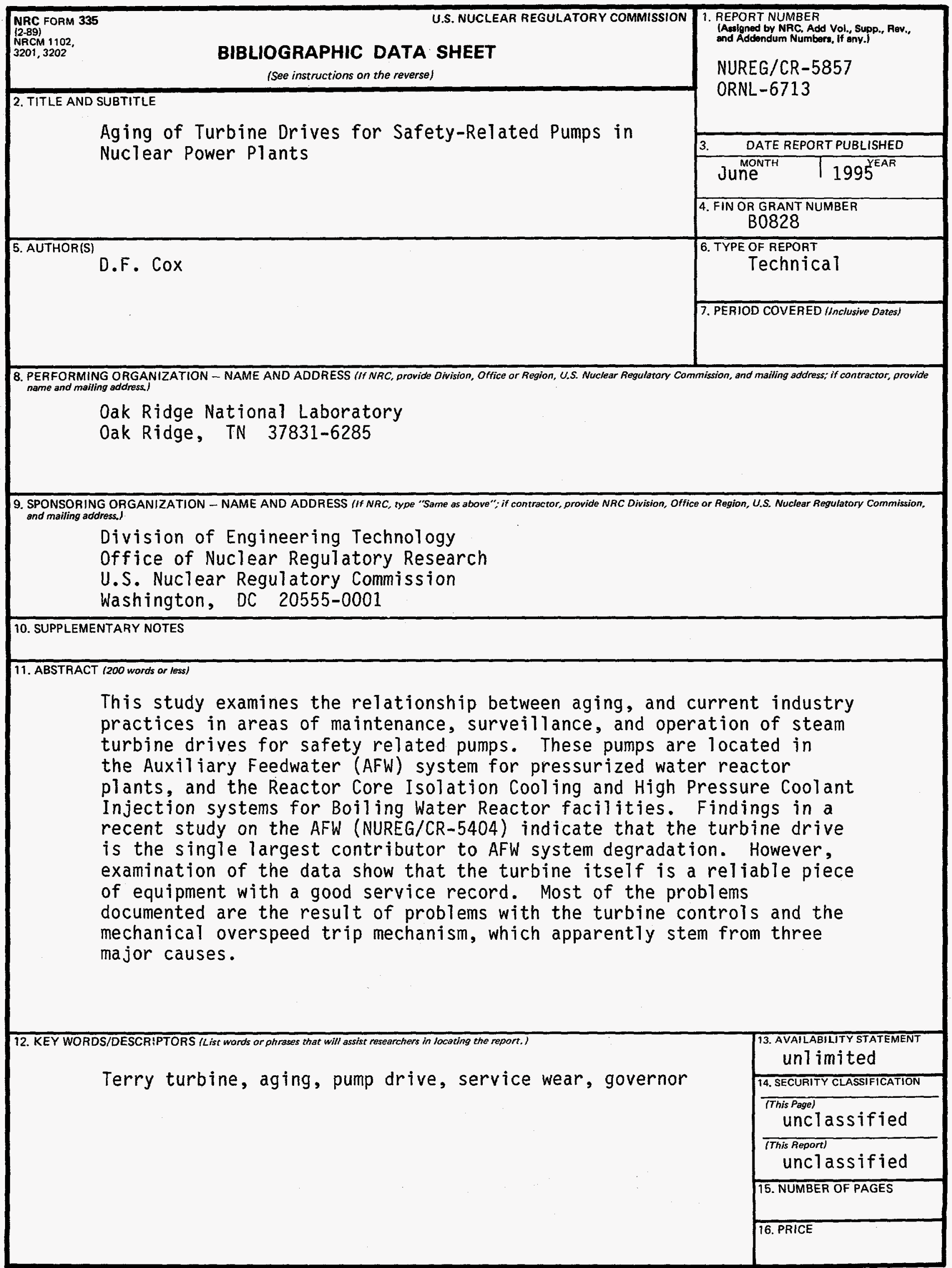

